\title{
Providing Reliability Services through Demand Response: A Preliminary Evaluation of the Demand Response Capabilities of Alcoa Inc.
}

January 2009
Prepared by
D. Todd
M. Caufield
B. Helms

Alcoa Power Generating, Inc.

M. Starke

B. Kirby

J. Kueck

Oak Ridge National Laboratory 


\section{DOCUMENT AVAILABILITY}

Reports produced after January 1, 1996, are generally available free via the U.S. Department of Energy (DOE) Information Bridge:

Web site: http://www.osti.gov/bridge

Reports produced before January 1, 1996, may be purchased by members of the public from the following source:

National Technical Information Service

5285 Port Royal Road

Springfield, VA 22161

Telephone: 703-605-6000 (1-800-553-6847)

TDD: 703-487-4639

Fax: 703-605-6900

E-mail: info@ntis.fedworld.gov

Web site: http://www.ntis.gov/support/ordernowabout.htm

Reports are available to DOE employees, DOE contractors, Energy Technology Data Exchange (ETDE)

representatives, and International Nuclear Information System (INIS) representatives from the following source:

Office of Scientific and Technical Information

P.O. Box 62

Oak Ridge, TN 37831

Telephone: 865-576-8401

Fax: 865-576-5728

E-mail: reports@adonis.osti.gov

Web site: http://www.osti.gov/contact.html

This report was prepared as an account of work sponsored by an agency of the United States Government. Neither the United States government nor any agency thereof, nor any of their employees, makes any warranty, express or implied, or assumes any legal liability or responsibility for the accuracy, completeness, or usefulness of any information, apparatus, product, or process disclosed, or represents that its use would not infringe privately owned rights. Reference herein to any specific commercial product, process, or service by trade name, trademark, manufacturer, or otherwise, does not necessarily constitute or imply its endorsement, recommendation, or favoring by the United States Government or any agency thereof. The views and opinions of authors expressed herein do not necessarily state or reflect those of the United States Government or any agency thereof. 


\title{
Providing Reliability Services through Demand Response: A Preliminary Evaluation of the Demand Response Capabilities of Alcoa Inc.
}

\author{
Prepared for the \\ Office of Electricity Delivery and Energy Reliability \\ Transmission Reliability Program \\ U.S. Department of Energy \\ Phil Overholt \\ Principal Authors \\ DeWayne Todd, Brian Helms, Mike Caufield, Michael Starke, Brendan Kirby, John Kueck
}

January 2009

Prepared by

Alcoa Power Generating, Inc. and

OAK RIDGE NATIONAL LABORATORY

Oak Ridge, Tennessee 37831-6070

managed by

UT-BATTELLE, LLC

for the

U.S. DEPARTMENT OF ENERGY

under contract DE-AC05-00OR22725 


\section{TABLE OF CONTENTS}

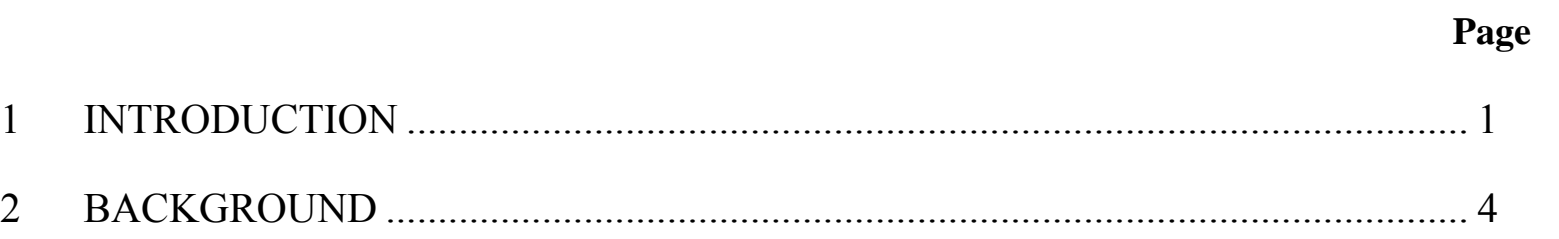

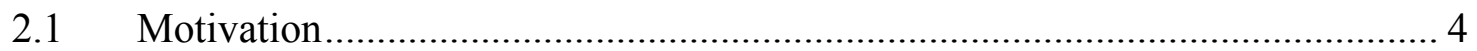

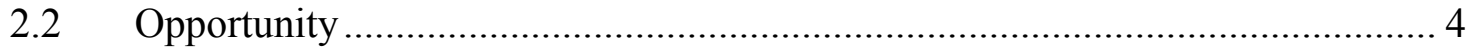

2.2.1 Why Power Systems Value Demand Response.......................................... 6

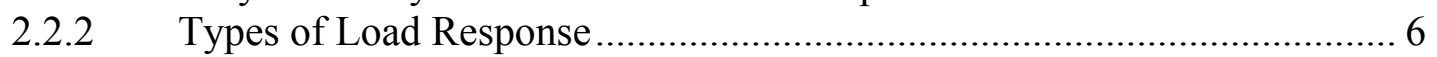

2.2.3 Ancillary Services ............................................................................... 7

2.2.4 Evaluation of Ancillary Services for Alcoa Power Generating, Inc......... 11

2.3 Aluminum Smelting May be Ideal Supplier of Regulation: Basics of Aluminum

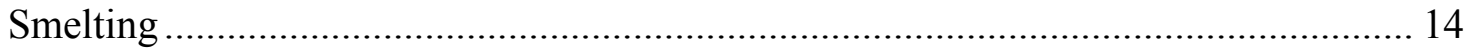

2.3.1 Aluminum Production Basics ................................................................... 15

2.3.2 Process Interruptions....................................................................... 17

2.3.3 Co-optimization of Energy and Ancillary Services ................................... 18

3 MIDWEST ISO ENERGY AND ANCILARY SERVICE MARKETS ................... 19

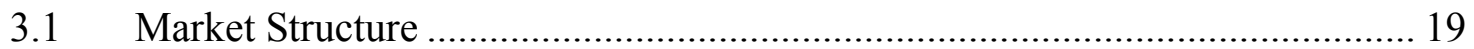

3.1.1 Midwest ISO History ……………………….................................... 19

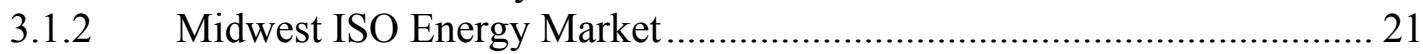

3.1.3 Midwest ISO Ancillary Services Market................................................. 22

3.2 Midwest ISO Balancing Authorities and Standards ....................................... 22

3.3 Providing Ancillary Services in the Midwest ISO Ancillary Service Market.. 24

3.3.1 Midwest ISO Classifications of Demand Response Participants ............. 25

3.3.2 Required Testing to be Eligible to Participate in ASM of Midwest ISO.. 25

3.3.3 Requirements on Resources that are involved in ASM of Midwest ISO . 27

3.3.4 Associated Penalties for Not Participating …………………………….... 27

3.4 Comparison with Other Markets.................................................................. 29

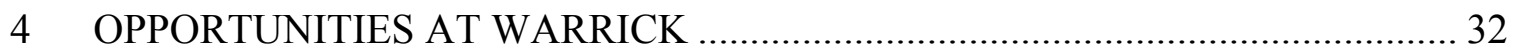

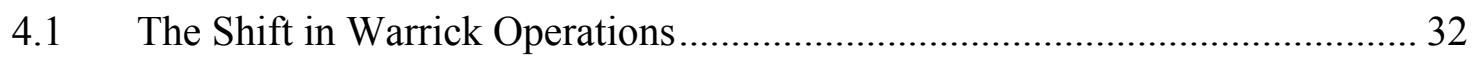

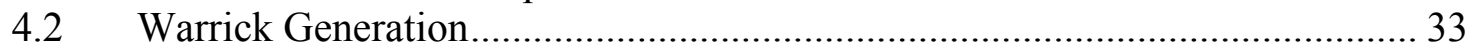

4.3 Warrick Transmission and Electrical System ............................................... 33

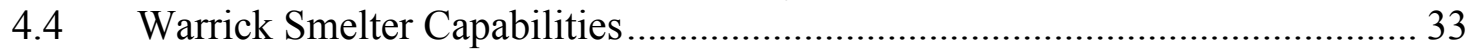

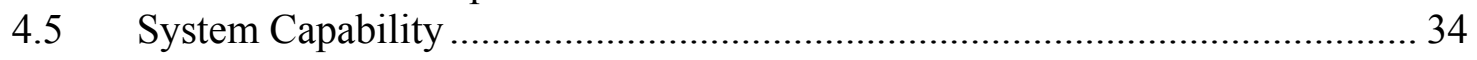

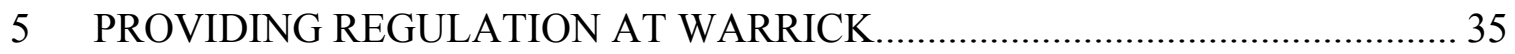

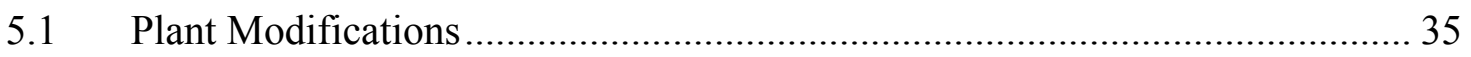

5.1.1 Bidding a Load Into The Midwest ISO Regulation Market ...................... 36

5.1.2 Communication and Metering ………………….................................. 37

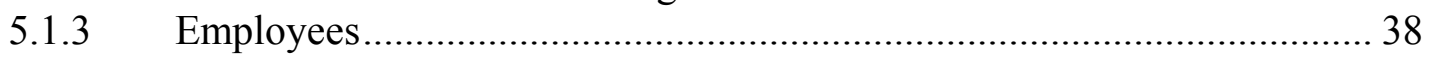




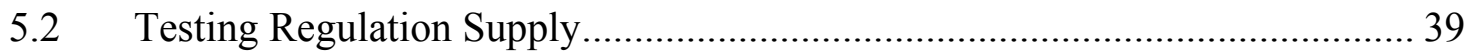

5.2.1 Midwest ISO Use of Regulation............................................................ 39

5.2.2 Warrick Provision of Regulation ........................................................... 41

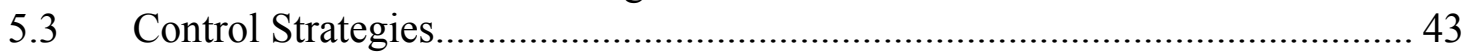

$5.4 \quad$ Regulation Effects on Production .................................................................. 44

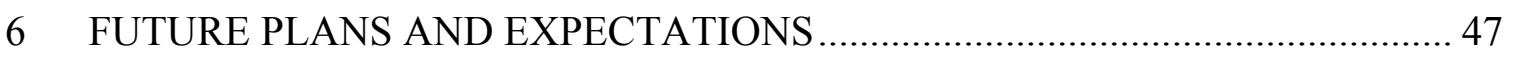

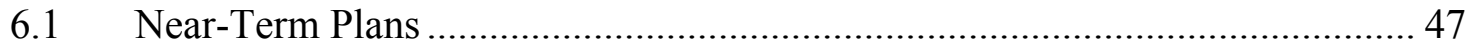

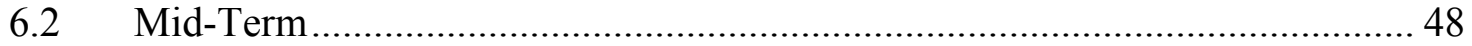

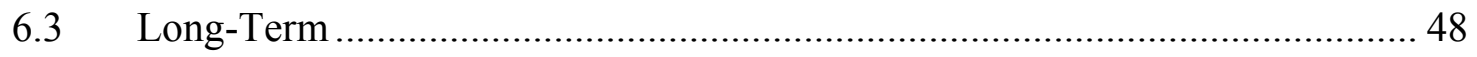

7 CONCLUSIONS AND RECOMENDATIONS ..................................................... 49 


\section{LIST OF FIGURES}

Figure Page

Figure 1 All five basic types of demand response impact power system reliability.......... 7

Figure 2 NERC demand side management categorization. (NERC, 2007) ...................... 8

Figure 3 Response time and duration differentiate ancillary services. ........................... 10

Figure 4. Regulation provides the minute-to-minute balancing of generation and load. . 12

Figure 5 Thermal generators often fail to follow regulation commands closely............. 13

Figure 6. Fifty MW of fast, accurate regulation reduces this Balancing Area regulation

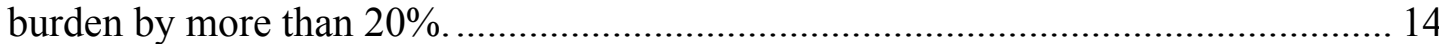

Figure 7 The cryolite bath must remain frozen at the edges to protect the pot wall and molten in the center to protect the anode and the pot itself. (Metals Advisor, 2008 and

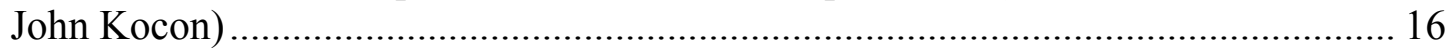

Figure 8 Primary aluminum production typically presents a flat load to the power system.

Figure 9 Midwest ISO footprint

Figure 10 Wholesale Market Supply and Demand................................................... 21

Figure 11 Testing procedure for regulation .............................................................. 26

Figure 12 Monthly average regulation prices are typically (but not always) somewhat

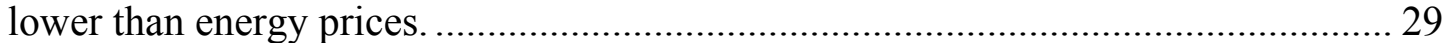

Figure 13 Ancillary service prices in all markets follow a pattern where regulation is most expensive and replacement reserve is least expensive......................................... 30

Figure 14 Example of regulation in the Midwest ISO Ancillary Services Market tests... 37

Figure 15 Energy Management System ......................................................................... 38

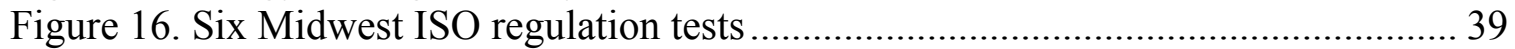

Figure 17. Cumulative regulation swing duration. .................................................. 40

Figure 18 Midwest ISO was using regulation to obtain energy on three of the six test

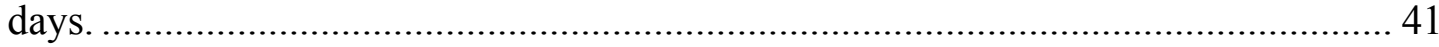

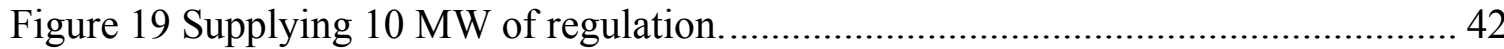

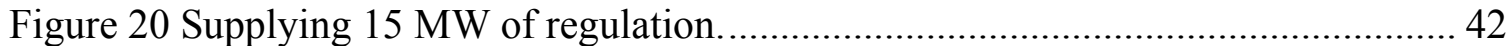

Figure 21 Potline interruption while supplying regulation......................................... 43

Figure 22 Providing regulation significantly increases potline tap changer movements. 46 


\section{LIST OF TABLES}

Table

Table 1 Definitions of Real-Power Ancillary Services.

Table 2. Midwest ISO Balancing Authorities................................................................. 23

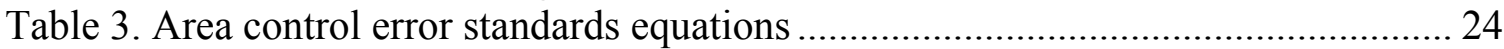

Table 4. Regulation resource requirements ............................................................. 27

Table 5. Contingency reserve requirements (Spinning and Supplemental).................... 28

Table 6 Annual average and maximum ancillary service prices from four markets for six

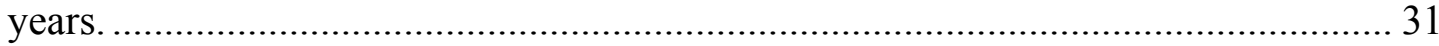

Table 7. Alcoa Power Generating, Inc. Energy Market Analysis.................................. 45 


\section{ACROYNMS}

$\begin{array}{ll}\text { ACE } & \text { Area Control Error } \\ \text { AGC } & \text { Automatic Generation Control } \\ \text { APGI } & \text { Alcoa Power Generating Inc. } \\ \text { ASM } & \text { Ancillary Service Market } \\ \text { BA } & \text { Balancing Authority } \\ \text { BAAL } & \text { Balancing Authority Area control error Limit } \\ \text { CPS1\&2 } & \text { Control Performance Standards 1 \& 2 } \\ \text { CRFF } & \text { Contingency Reserve Failure Flag } \\ \text { DCS } & \text { Disturbance Control Standard } \\ \text { DRR } & \text { Demand Response Resources } \\ \text { EMS } & \text { Energy Management System } \\ \text { ERCOT } & \text { Electric Reliability Council Of Texas } \\ \text { FFDF } & \text { Failure to Follow Dispatch Flag } \\ \text { FERC } & \text { Federal Energy Regulatory Commission } \\ \text { FRCC } & \text { Florida Reliability Coordinating Council } \\ \text { FTR } & \text { Financial Transmission Rights } \\ \text { LCPD } & \text { Smelter Potline Load Control System } \\ \text { LSE } & \text { Load Servicing Entity } \\ \text { MCP } & \text { Market Clearing Price } \\ \text { Midwest ISO } & \text { Midwest Independent System Operator } \\ \text { MP } & \text { Market Participant } \\ \text { MRO } & \text { Midwest Reliability Organization } \\ \text { NERC } & \text { North American Electric Reliability Corporation } \\ \text { NPCC } & \text { Northeast Power Coordinating Council } \\ \text { PJM } & \text { Pennsylvania New Jersey Maryland Interconnection LLC } \\ \text { RFC } & \text { Reliability First Corporation } \\ \text { RPI } & \text { Regulation Performance Index } \\ \text { SERC } & \text { SERC Reliability Corporation } \\ \text { SPP RE } & \text { Southwest Power Pool Regional Entity } \\ \text { TRE } & \text { Texas Reliability Entity } \\ \text { WECC } & \text { Western Electricity Coordinating Council } \\ & \end{array}$




\section{INTRODUCTION}

Demand response is the largest underutilized reliability resource in North America. Historic demand response programs have focused on reducing overall electricity consumption (increasing efficiency) and shaving peaks but have not typically been used for immediate reliability response. Many of these programs have been successful but demand response remains a limited resource. The Federal Energy Regulatory Commission (FERC) report, "Assessment of Demand Response and Advanced Metering" (FERC 2006) found that only five percent of customers are on some form of demand response program. Collectively they represent an estimated 37,000 MW of response potential. These programs reduce overall energy consumption, lower green house gas emissions by allowing fossil fuel generators to operate at increased efficiency and reduce stress on the power system during periods of peak loading.

As the country continues to restructure energy markets with sophisticated marginal cost models that attempt to minimize total energy costs, the ability of demand response to create meaningful shifts in the supply and demand equations is critical to creating a sustainable and balanced economic response to energy issues. Restructured energy market prices are set by the cost of the next incremental unit of energy, so that as additional generation is brought into the market, the cost for the entire market increases. The benefit of demand response is that it reduces overall demand and shifts the entire market to a lower pricing level. This can be very effective in mitigating price volatility or scarcity pricing as the power system responds to changing demand schedules, loss of large generators, or loss of transmission.

As a global producer of alumina, primary aluminum, and fabricated aluminum products, Alcoa Inc., has the capability to provide demand response services through its manufacturing facilities and uniquely through its aluminum smelting facilities. For a typical aluminum smelter, electric power accounts for $30 \%$ to $40 \%$ of the factory cost of producing primary aluminum. In the continental United States, Alcoa Inc. currently owns and/or operates ten aluminum smelters and many associated fabricating facilities with a combined average load of over 2,600 MW. This presents Alcoa Inc. with a significant opportunity to respond in areas where economic opportunities exist to help mitigate rising energy costs by supplying demand response services into the energy system.

Because of the large quantity of energy used in its smelting and manufacturing facilities, Alcoa Power Generating Inc (APGI), was created as a subsidiary of Alcoa Inc., to focus on procurement of energy and energy services. APGI is a FERC regulated public utility that serves load at many of Alcoa's aluminum facilities. The identification of opportunities to reduce the cost of energy has led to a significant focus on energy efficiency and market opportunities at all of Alcoa's facilities. The opportunity to reduce the cost of purchased electric power while increasing power system reliability has been realized at Alcoa's Warrick Operations (located in Southern Indiana) through direct participation in the Midwest ISO Energy Market and the preparation for participation in 
the developing Midwest ISO Energy and Ancillary Services Markets. By reacting as a demand response resource, APGI currently participates in the energy market and plans to increase the level of participation by supplying ancillary services including spinning reserves, emergency demand response and of particular significance, regulation services, for financial compensation. The primary objective of the effort discussed in this report is to design and demonstrate a more energy efficient, reliable, and economically sound method for meeting the minute-to-minute real-power regulation requirements of the electricity grid with responsive load, particularly an aluminum smelter. While the supply of spinning reserves and emergency demand response are important and critical services, they are straightforward in the application and are easily supplied through interruption of the load. This demand response effort happens to be coincident with the opening of Midwest ISO's Ancillary Service Markets.

Demand response has begun to be considered, and in some cases actually implemented, to directly supply reliability services to the power system. Rather than reducing overall power system stress by reducing peak loading over multiple hours these programs are targeted to immediately respond to specific reliability events through the supply of contingency reserves (spinning, non-spinning, and supplemental reserves). This is made possible by advances in communications and controls and has benefits for the power system and the load. Unfortunately, preconceptions concerning load response capabilities and the willingness of customers to have load curtailed or interrupted, coupled with misunderstandings of power system reliability needs, have led to the creation of many unnecessary barriers to entry into ancillary service markets. Outdated reliability rules that are based on the capabilities and limitations of the historic resources (typically generation or classical demand response programs), limit the use of responsive loads. In many places loads are still prohibited from providing the most valuable reliability services in spite of evidence that their response can be superior to that of generators. These factors are denying the power system a valuable reliability resource. They are also denying loads the ability to sell valuable services.

Alcoa Power Generating, Inc.'s efforts to provide regulation from responsive load represent a significant advance in demand response. Regulation is the most expensive and most difficult to supply ancillary service. It requires the load to continuously respond to power system operator automatic generation control (AGC) signals to move up and down. Response must be fast and accurate. Evaluating the potential for a load to provide regulation involves 1) a technical assessment of the underlying process' physics to determine if control is possible, 2) an assessment of the capabilities of the specific factory where the implementation is proposed, 3 ) an evaluation of the required communications and control equipment including the equipment costs, 4) an evaluation of any increased process losses and maintenance costs, 5) an evaluation of the lost opportunities when the factory production capacity is switched from making product (aluminum in this case) and is instead used to supply regulation, and 6) a comparison of the expected benefits from selling regulation with the expected costs (including program startup costs) involved in supplying regulation. The physical and economic analyses are heavily intertwined. 
This report is organized into seven chapters. The first chapter is the introduction and discusses the intention of this report. The second chapter contains the background. In this chapter, topics include: the motivation for Alcoa to provide demand response; ancillary service definitions; the basics behind aluminum smelting; and a discussion of suggested ancillary services that would be particularly useful for Alcoa to supply. Chapter 3 is concerned with the independent system operator, the Midwest ISO. Here the discussion examines the evolving Midwest ISO market structure including specific definitions, requirements, and necessary components to provide ancillary services. This section is followed by information concerning the Midwest ISO's classifications of demand response parties. Chapter 4 investigates the available opportunities at Alcoa's Warrick facility. Chapter 5 involves an in-depth discussion of the regulation service that Alcoa's Warrick facility can provide and the current interactions with Midwest ISO. Chapter 6 reviews future plans and expectations for Alcoa providing ancillary services into the market. Last, chapter 7, details the conclusion and recommendations of this paper. 


\section{BACKGROUND}

\subsection{Motivation}

Aluminum production is an extremely competitive business in the world market. The United States, once the leading aluminum producer, has been surpassed by China, Russia, and Canada. This is primarily a result of the construction of newer facilities that tend to focus on reducing cost through utilizing cheaper labor and electricity. Aging equipment, older technology, rising labor costs and most significantly the continued rise of energy costs within the United States are forcing Alcoa Inc. to continually evaluate the effectiveness of their current facilities to compete in a global aluminum market. The long term viability of Alcoa's facilities within the United States is contingent on finding methods to reduce costs. Already, Alcoa facilities located in the PJM and ERCOT markets have been forced to close as a result of skyrocketing power costs.

In reducing cost, Alcoa has targeted all elements of the cost structure with an emphasis on electrical energy, which accounts for one of the single largest component costs in aluminum production at 30 to $40 \%$. Unfortunately there is limited ability to further reduce the raw electrical component price in aluminum production within existing facilities, because those facilities operate at peak design efficiency as a result of extensive process improvement initiatives. Instead, the focus has turned to reducing electricity costs. By dynamically participating in energy markets and in evaluating the opportunities for supplying ancillary services that can cost effectively contribute to bulk-power system reliability, Alcoa can mitigate otherwise rising energy costs. Through a significant shift in the fundamental operation of aluminum smelters, it may be possible to sustain profitable operation of these important assets.

However, an examination of the requirements, affects on aluminum production, and capability of Alcoa to market these demand response services into energy and ancillary services markets is required. This report seeks to evaluate the opportunities in cost reduction that Alcoa may be able to realize through participation in energy and ancillary services markets.

\subsection{Opportunity}

Several factors contribute to this opportunity to investigate the supply of ancillary services (including real-power regulation) to the bulk power system through modified control of the aluminum smelting process. As mentioned above, the large and increasing contribution of electricity costs to the cost of producing aluminum provided the basic economic motivation to seek ways to reduce that cost. The establishment of energy markets in general and the evolving implementation of ancillary service markets across the country has led to a focused effort to understand the capabilities of Alcoa's various

assets in providing specific load response services. Alcoa has chosen to focus particular 
attention at its Warrick Operations site as a "test site" located in the Midwest ISO markets.

Ancillary service markets monetize the economic value of specific response. Data from markets in multiple regions and covering multiple years shows that the response value is genuine, stable, and realizable. Establishment of the Midwest ISO ancillary services markets provides a specific opportunity for Alcoa's Warrick aluminum smelter. The load requirements of Alcoa's Warrick operation are served by APGI. The favorable experiences of operating in the Midwest ISO energy markets, with both APGI's generation plant and the aluminum load, coupled with the high level of stability of the aluminum smelting process at Warrick has provided a basis of experience for expanding electricity market interactions and increasing the profits from response to market price signals.

Aluminum smelters consume massive amounts of electrical energy. This electrical energy is utilized in an electrolysis process that must be continually managed to avoid breaching facility limits. Aluminum production is a direct function of the amount of power consumed. Power consumption by the electrolysis process has historically been focused on maintaining a flat and highly stable load profile with minimal variation throughout an hour or a day in order to maximize production efficiency and process stability. Although consumption varies annually, following the world aluminum market, the hourly process variation is minimal with very high load factors. Because of the direct relationship between energy and production, sustained power reductions result in lost metal production; however, it is hypothesized that the electric power consumption could be varied rapidly to provide regulation services to the power system without significantly reducing the quantity of the aluminum produced, as long as the average power input remained constant over a long time frame (multiple hours). It is recognized that a reduction in process efficiency and stability, as well as increased maintenance costs are risks to supplying regulation services.

Any ancillary service that reduces power supplied to the smelting process would have a lost opportunity cost that represents the reduced aluminum production. Aluminum smelting basics will be discussed later but for the present it is sufficient to state that there are five basic limits on the how much process power can be varied in order to supply regulation and spinning reserves:

- Process power can not be increased beyond the capabilities of the electric equipment supplying the process (transformers, rectifiers, bus work, etc.)

- Process power can not be reduced below the control capability range of the electric supply equipment currently in place (tap changers, etc.)

- Variation of process power must not be increased beyond the capabilities of the smelting reaction to maintain a stable reaction (i.e. as heat input changes are made, the line must be allowed to stabilize before proceeding)

- Multi-hour average power can not be increased beyond the ability of the potline to accept thermal energy (a frozen layer of cryolite must be maintained at the pot wall, as explained later) 
- Multi-hour average power can not be reduced below that required to keep the potline thermally viable (cryolite must not freeze completely)

Violating these equipment and process limits could result in extremely expensive damage to equipment and processes. ${ }^{1}$ Despite the fact that the Warrick smelter was not designed for flexible load profiles, even within these limits, the capability to respond to requests for load changes is impressive. Providing that the physical capability of Warrick is not violated while providing regulation, this can be a tremendous reliability asset to the power system and provides APGI with a methodology to reduce energy supply costs.

\subsubsection{Why Power Systems Value Demand Response}

The stability of the power system relies on the ability of aggregate generation to match total load successfully. Without generation matching the load, power system frequency will deviate significantly and can lead to system collapse. Nevertheless, demand by most energy consumers is never a constant as loads are endlessly energized and deactivated. Since there is still little efficient and economical energy storage, generation response to the load must be conducted continuously.

Ancillary services provide the system operator with control over the real-time generation/load balance equation. Traditionally generators have dominated supplying ancillary services allowing system operators to control the supply of energy to match the current demand. This balance of supply and demand can be done equally effectively by controlling the load side of the equation, however. Demand response is valued for the same reasons, and to the same extent as generation response.

\subsubsection{Types of Load Response}

There are five basic types of load response as shown in Figure 1. All of these responses have some impact on power system reliability and some have a greater impact than others. Energy efficiency reduces energy consumption during all hours and typically reduces the need for generation and transmission. However, energy efficiency is not focused on times of greatest power system stress and may not provide a reliability response to specific reliability problems as cost effectively as more directed alternatives. Price responsive load and peak shaving resources target specific hours when the response is desired: the former facilitates voluntary market response to price signals while the latter utilizes direct control commands. Both types of response can be used to address capacity inadequacy caused by a lack of generation or a lack of transmission. Reliability response (contingency response) and regulation specifically target power system reliability needs and offer the greatest reliability benefit per MW of load from loads that are capable of providing these types of response.

\footnotetext{
${ }^{1}$ It is possible that a new potline and associated power supply could be designed that eliminate these limitations greatly increasing the ability of the plant to supply regulation. This is discussed further in chapter 6 .
} 
- Energy Efficiency programs reduce electricity consumption and usually reduce peak demand

- Price Response programs move consumption from day to night (real time pricing or time of use)

- Peak Shaving programs require more response during peak hours and focus on reducing peaks every high-load day

- Reliability Response (contingency response) requires the fastest, shortest duration response. Response is only required during power system "events" - this is new and slowly developing

- Regulation Response continuously follows the power system's minute-to-minute commands to balance the aggregate system - this is very new and may have the potential to dramatically change production costs, especially for aluminum and chlor-alkali
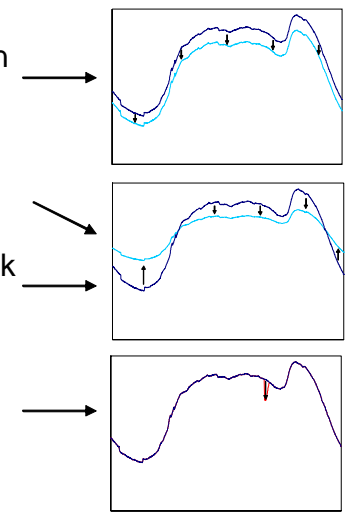

\section{Figure 1 All five basic types of demand response impact power system reliability}

The North American Electric Reliability Corporation (NERC) has defined the categorization scheme shown in Figure 2 to describe the various types of demand side management. (NERC, 2007) The scheme covers both dispatchable and non-dispatchable demand response. NERC is continuing to develop performance statistics for each type of response.

\subsubsection{Ancillary Services}

Ancillary services are "extra" functions which must be performed in order to reliably operate the bulk electric system and ensure continued supply of the electric power that customers actually value. These are not new services; they have always been required for reliable power system operations. Restructuring of the electric power industry has required that these various functions, previously provided by the vertically integrated utility, be specifically defined and unbundled to facilitate competition. The establishment of energy markets has created a missed opportunity for those resources that are supplying ancillary services at fixed (regulated) rates during times of peak market opportunity where a generator may be operating at reduced load to maintain contingency reserves necessary to maintain the system. While necessary, this may not be the most cost effective method to supply these services. For this reason, markets for key ancillary services form an integral part of the whole energy market model. 


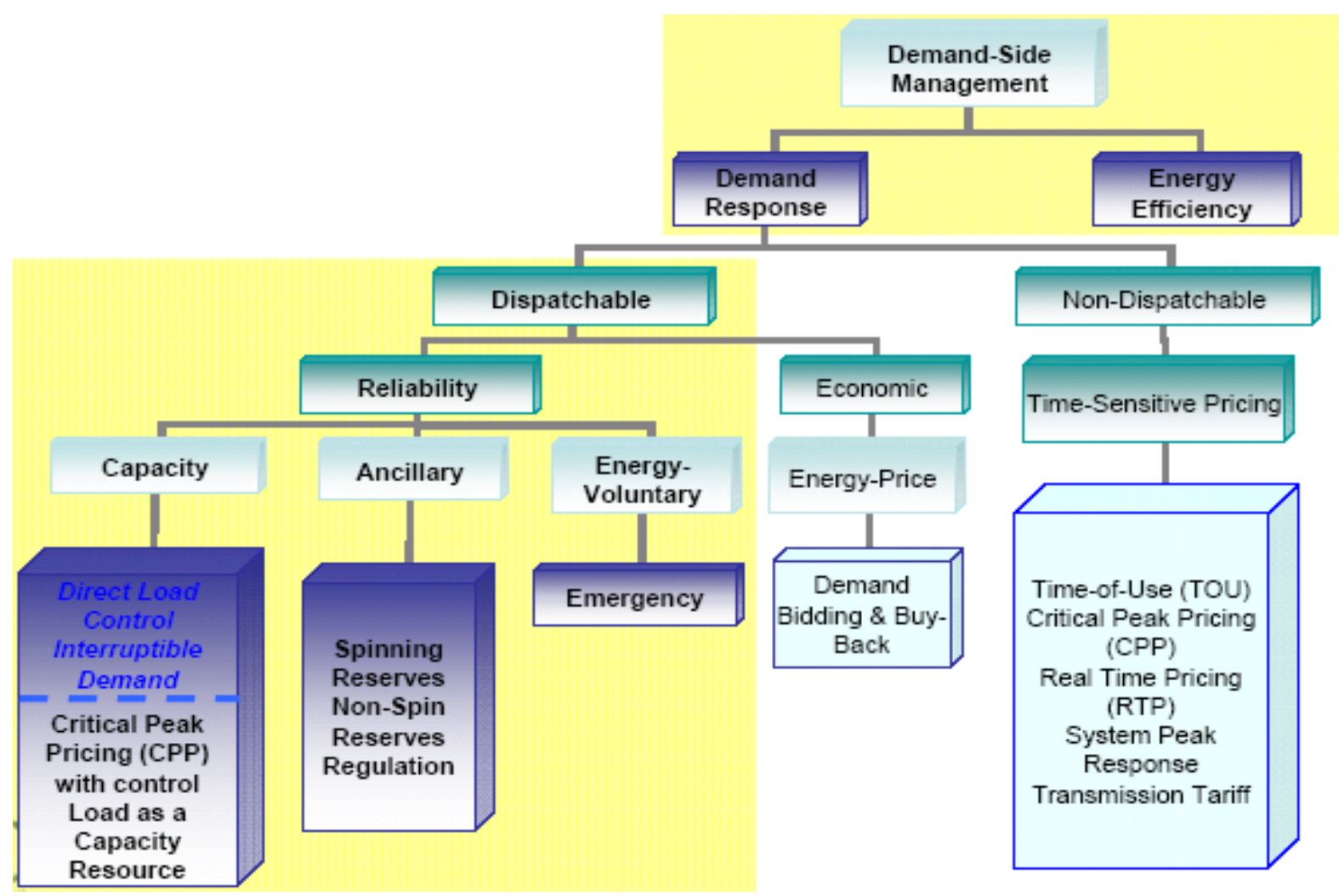

Figure 2 NERC demand side management categorization. (NERC, 2007)

FERC defined the ancillary services as those functions performed by the equipment and people that generate, control, and transmit electricity in support of the basic services of generating capacity, energy supply, and power delivery. These services are required to respond to the two unique characteristics of bulk-power systems: the need to maintain a balance between generation and load in near real-time and the need to manage power flows through individual transmission facilities by redispatching generation and load. (Hirst and Kirby, 2003) FERC specifically recognized six key ancillary services in its landmark Order 888 (FERC 1996): (1) Scheduling, System Control and Dispatch Service; (2) Reactive Supply and Voltage Control from Generation Sources Service; (3) Regulation and Frequency Response Service; (4) Energy Imbalance Service; (5) Operating Reserve - Spinning Reserve Service; and (6) Operating Reserve Supplemental Reserve Service. Table 1 lists the key real-power ancillary services, the ones that ISOs generally buy in competitive markets.

The services which responsive loads may be willing and able to provide are noted in blue in Table 1. Each load must evaluate the costs and benefits of providing each ancillary service but more expensive services are, naturally, typically more attractive to sell. The five real-power ancillary services are distinguished by the response speed, duration, and frequency of deployment. Exact definitions vary somewhat from region to region but the general timing for these services and voltage control are shown in Figure 3. Particular definitions and discussion concerning the Midwest ISO can be found in Chapter 3 . 
Table 1 Definitions of Real-Power Ancillary Services

\begin{tabular}{|c|c|c|c|c|c|}
\hline \multirow[b]{2}{*}{ Service } & \multicolumn{5}{|c|}{ Service Description } \\
\hline & Response Speed & Duration & Cycle Time & Market Cycle & $\begin{array}{l}\text { Price Range* } \\
\text { (average/max) } \\
\quad \$ / M W-h r\end{array}$ \\
\hline \multicolumn{6}{|c|}{ Normal Conditions } \\
\hline \multirow[t]{2}{*}{$\begin{array}{l}\text { Regulating } \\
\text { Reserve }^{+}\end{array}$} & \multicolumn{5}{|c|}{$\begin{array}{l}\text { Online resources, on automatic generation control, that can respond rapidly to system- } \\
\text { operator requests for up and down movements; used to track the minute-to-minute } \\
\text { fluctuations in system load and to correct for unintended fluctuations in generator } \\
\text { output to comply with Control Performance Standards (CPSs) } 1 \text { and } 2 \text { (or CPM and } \\
\text { BAAL) of the North American Electric Reliability Corporation (NERC 2008) }\end{array}$} \\
\hline & $\sim 1 \mathrm{~min}$ & Minutes & Minutes & Hourly & $\begin{array}{c}35-40^{\#} \\
200-400\end{array}$ \\
\hline \multirow{2}{*}{$\begin{array}{l}\text { Load } \\
\text { Following or } \\
\text { Fast Energy } \\
\text { Markets }\end{array}$} & \multicolumn{5}{|c|}{$\begin{array}{l}\text { Similar to regulation but slower. Bridges between the regulation service and the hourly } \\
\text { energy markets. Often supplied at little or no cost by sub-hourly energy markets. }\end{array}$} \\
\hline & $\sim 10$ minutes & 10 min to hours & $\begin{array}{l}10 \text { min to } \\
\text { hours }\end{array}$ & Hourly & 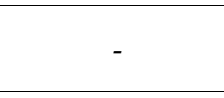 \\
\hline \multicolumn{6}{|c|}{ Contingency Conditions } \\
\hline \multirow[t]{2}{*}{$\begin{array}{l}\text { Spinning } \\
\text { Reserve }\end{array}$} & \multicolumn{5}{|c|}{$\begin{array}{l}\text { Online generation (or load), synchronized to the grid, that can increase output (or } \\
\text { reduce consumption) immediately in response to a major generator or transmission } \\
\text { outage and can reach full output within } 10 \text { min to comply with NERC's Disturbance } \\
\text { Control Standard (DCS) }\end{array}$} \\
\hline & $\begin{array}{l}\text { Seconds to }<10 \\
\text { min }\end{array}$ & 10 to $120 \mathrm{~min}$ & $\begin{array}{l}\text { Hours to } \\
\text { Days }\end{array}$ & Hourly & $\begin{array}{c}6-17 \\
100-300\end{array}$ \\
\hline \multirow[t]{2}{*}{$\begin{array}{l}\text { Non-Spinning } \\
\text { Reserve }\end{array}$} & \multicolumn{5}{|c|}{$\begin{array}{l}\text { Same as spinning reserve, but need not respond immediately; resources can be offline } \\
\text { but still must be capable of providing full response within the required } 10 \mathrm{~min}\end{array}$} \\
\hline & $<10 \min$ & 10 to $120 \mathrm{~min}$ & $\begin{array}{l}\text { Hours to } \\
\text { Days }\end{array}$ & Hourly & $\begin{array}{c}3-6 \\
100-400\end{array}$ \\
\hline \multirow{2}{*}{$\begin{array}{l}\text { Replacement } \\
\text { or } \\
\text { Supplemental } \\
\text { Reserve }\end{array}$} & \multicolumn{5}{|c|}{$\begin{array}{l}\text { Same as supplemental reserve, but with a } 30-60 \text { min response time; used to restore } \\
\text { spinning and non-spinning reserves to their pre-contingency status }\end{array}$} \\
\hline & $<30 \min$ & 2 hours & $\begin{array}{l}\text { Hours to } \\
\text { Days }\end{array}$ & Hourly & $\begin{array}{l}0.4-2 \\
2-36\end{array}$ \\
\hline \multicolumn{6}{|c|}{ Other Services } \\
\hline \multirow[t]{2}{*}{$\begin{array}{l}\text { Voltage } \\
\text { Control }\end{array}$} & \multicolumn{5}{|c|}{$\begin{array}{l}\text { The injection or absorption of reactive power to maintain transmission-system voltages } \\
\text { within required ranges }\end{array}$} \\
\hline & Seconds & Seconds & Continuous & Year(s) & $\$ 1-\$ 4 / k v a r-y r$ \\
\hline \multirow[t]{2}{*}{ Black Start } & \multicolumn{5}{|c|}{$\begin{array}{l}\text { Generation, in the correct location, that is able to start itself without support from the } \\
\text { grid and which has sufficient real and reactive capability and control to be useful in } \\
\text { energizing pieces of the transmission system and starting additional generators. }\end{array}$} \\
\hline & Minutes & Hours & $\begin{array}{l}\text { Months to } \\
\text { Years }\end{array}$ & Year(s) & - \\
\hline
\end{tabular}

* Prices are approximate ranges in \$/MW-hr and include California, ERCOT, and New York.

${ }^{+}$Ancillary services which loads may wish to sell are shown in blue

\# Up and down regulation prices for California and ERCOT are combined to facilitate comparison with the full-range prices of New York 
Scheduling, System Control and Dispatch Service is the provision of the system operator control center etc. This is not a service that loads or generators can provide.

Reactive Supply and Voltage Control from Generation Sources Service deals with the supply and control of dynamic reactive power. This is needed to maintain stable voltages throughout the power system. Some loads with large solid state drives may be able to provide dynamic reactive power to the power system and they should discuss this with their transmission provider. Reactive power requirements are much more location specific than real power requirements so each case tends to require individual negotiations.

Requlation provides the continuous minute-to-minute balancing of generation and load under normal conditions. This is the most expensive ancillary service. Most balancing authorities dedicate about $1 \%$ to $1.5 \%$ of their generation to supplying regulation. Some loads may be capable of supplying regulation.

Regulation is the most difficult ancillary service to supply from a communication and control perspective. It requires continuous response to the power system operator's AGC commands (Figure 4). But it is also the most expensive ancillary service so it is the most financially rewarding if a load is able to provide the service. Supplying regulation is also better matched to some loads' fundamental capabilities because the required response does swing back-and-forth regularly. A multi-hour curtailment, which is difficult for many loads to provide, is not required.

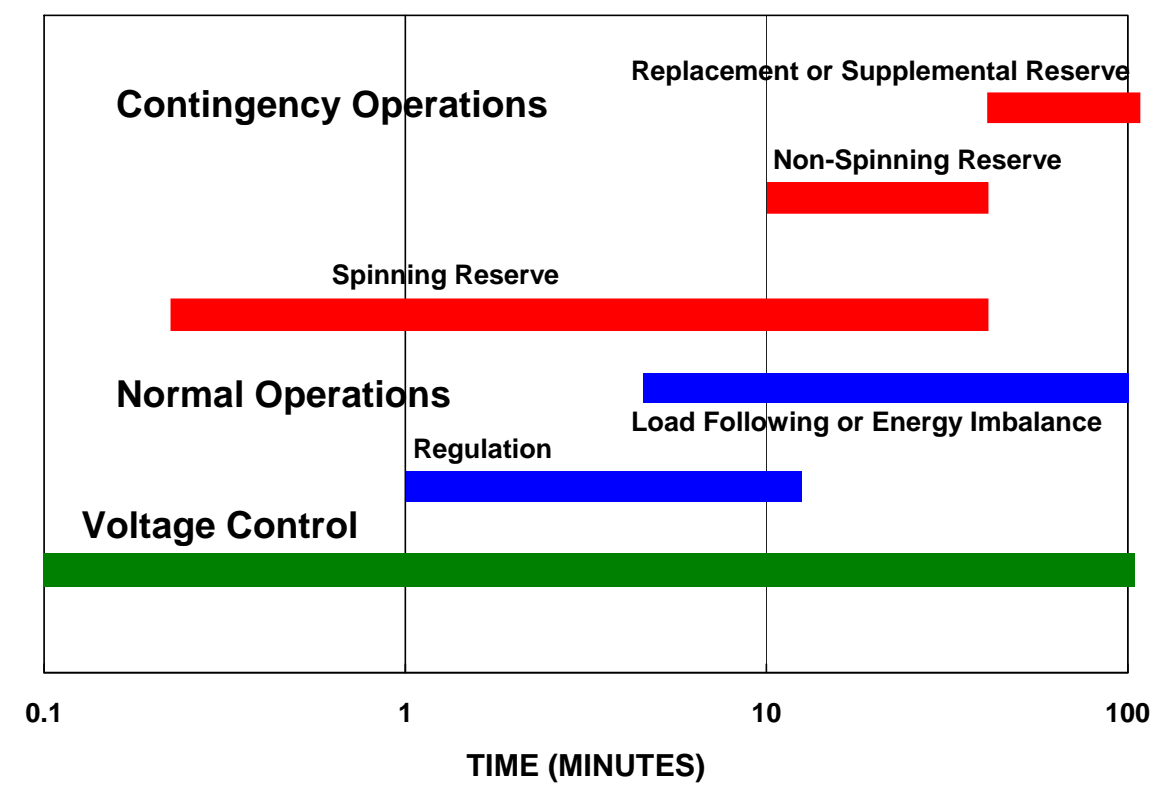

Figure 3 Response time and duration differentiate ancillary services. 
Energy Imbalance Service is really an accounting function that accommodates any differences between scheduled and actual transactions. It is not a "service" that individual generators or loads provide. Load following is a related service that compensates for the inter- and intra-hour changes in demand. This is the slower counterpart to regulation. Load following is often provided by sub-hourly energy markets and the effective price for load following is typically very low.

Spinning Reserve Service is generation (or responsive load) that is poised, ready to respond immediately, in case a generator or transmission line fails unexpectedly. Spinning reserve begins to respond immediately and must fully respond within ten minutes. Enough contingency reserve (spinning and non-spinning) must be available to deal with the largest failure that is anticipated. Some regions allow appropriate loads to supply spinning reserve but many currently do not.

Non-Spinning Reserve Service, is similar to spinning reserve except that response does not need to begin immediately. Full response is still required within 10 minutes. Appropriately responsive loads are typically allowed to supply non-spinning reserve.

Replacement or Supplemental Reserve is an additional reserve required in some regions. It begins responding in 30 to 60 minutes. It is distinguished from non-spinning reserve by the response time frame. Appropriately responsive loads are typically allowed to supply replacement or supplemental reserve.

\subsubsection{Evaluation of Ancillary Services for Alcoa Power Generating, Inc.}

Communications and control are the critical characteristics that determine if a load is capable of providing reliability reserves. Load must be controllable if it is to supply reliability services to the power system. The control must be fast, reliable and accurate. The load must also have a way to receive deployment commands from the power system operator. Faster services (spinning reserve and regulation) require automatic response to system operator commands. Some systems require automatic relaying response in order to be a qualified resource (i.e supply of Under Voltage Load Shedding or Under Frequency Load Shedding response). Frequency response services require that the load sense and respond autonomously to reductions in power system frequency.

From the load's perspective important additional characteristics include sensitivity to electricity price, storage capability, production levels and efficiency. Storage of product or energy within the load is valuable to free the load to respond to power system needs without hurting the load's primary function. Load sensitivity to electricity prices and compensation for response are typically required to get the load's interest.

Air conditioning loads (residential and commercial, central and distributed) can be ideal suppliers of spinning and non-spinning reserves. Many pumping loads are also good candidates (water, natural gas, and other gasses). Any industrial process with some 
manufacturing flexibility is a good candidate (cement, paper, steel, aluminum, refining, air liquefaction, etc.). The list is endless.

Regulation, the minute-to-minute varying of generation or consumption at the system operator's command in order to maintain the balancing area's (control area's) generation/load balance, is the most difficult ancillary service for loads to provide. Automatic generation control commands are typically sent from the system operator to the regulating generators about every four seconds (Figure 4). Regulation is also the most expensive ancillary service so it may be the most attractive service to sell for loads that are capable of supplying it.

Some loads may have the inherent capability to provide regulation. Loads that are electronically controlled could potentially follow automatic generation control commands very accurately. Loads with large adjustable speed drives or solid state power supplies are candidates. Product quality must be independent of the rate of electricity consumption to allow the power system operator to adjust the load's consumption but energy efficiency and production levels can be impacted by the rate of electricity consumption. Efficiency reductions simply impact the cost of regulation from the process.

To provide regulation services a load must have the ability to operate at discreet energy consumption levels with a level of control that equals that provided by generators. This includes the ability to both increase power consumption to a spot higher than current production levels and the capacity to reduce load from current consumption levels (In ERCOT you can bid up and down separately). When providing regulation, the load may

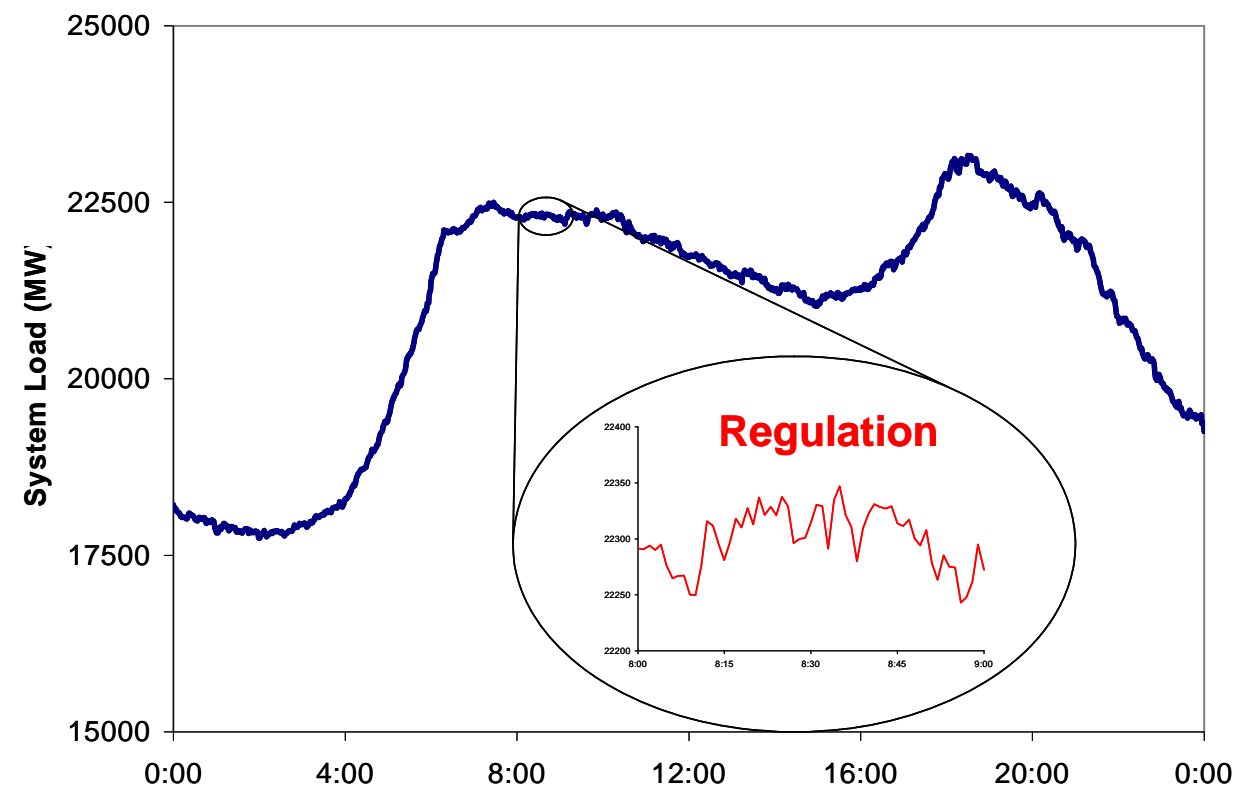

Figure 4. Regulation provides the minute-to-minute balancing of generation and load. 
need to back down from full production capacity and average a lower production level in order to have sufficient capacity to move up in load when directed by the system operator. Similarly, the load can not be at minimum production capacity because there must be room to reduce consumption when directed.

A number of load types in the U.S. may have the capability and inclination to provide regulation:

- Induction \& ladle metallurgy furnaces: 1,000MW

- Air liquefaction: 1,000MW

- Gas \& water pumping with variable speed motor drives

- Electrolysis: $>14,000 \mathrm{MW}$

- Aluminum: 6,500MW

- Chlor-alkali: 4,500MW

- Potassium hydroxide: $1,000 \mathrm{MW}$

- Magnesium, sodium chlorate, copper

Interestingly, it is likely that electronically controlled responsive loads could provide regulation of significantly greater value than that provided by conventional generation. Thermal generators often do not follow regulation requests closely as shown in Figure 5. A load with a solid state control may follow regulation commands perfectly. This may reduce the power system's regulation requirements. If the load incurs little incremental cost for response (given the capital cost to make the load ready to respond, the efficiency losses associated with controlling the process, and the opportunity costs associated with reducing production and/or changing schedules) the load may become the preferred regulation resource.

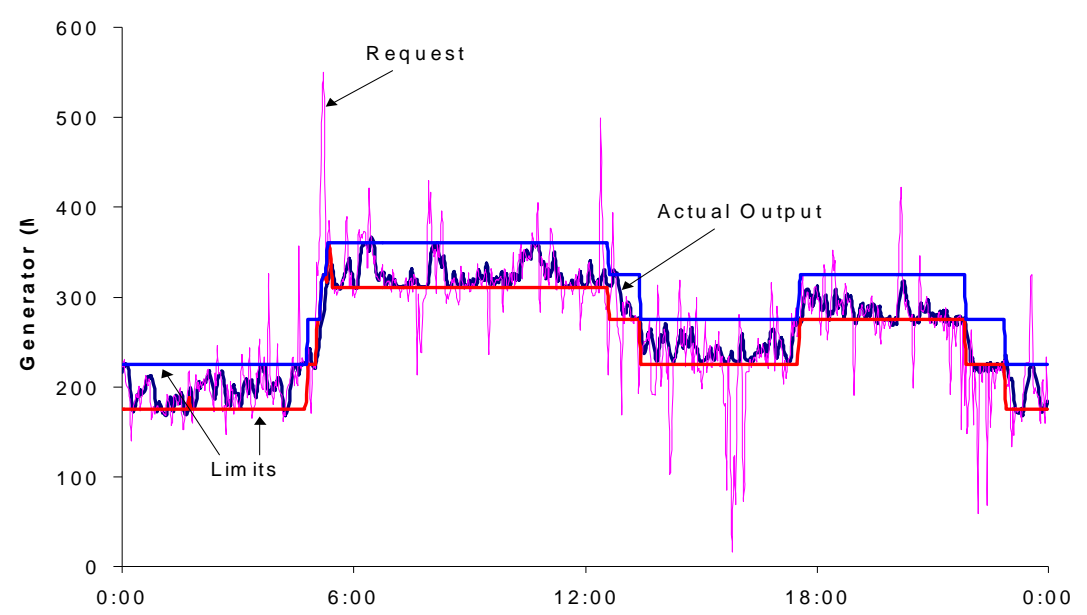

Figure 5 Thermal generators often fail to follow regulation commands closely. 
Figure 6 compares the actual power system regulation requirement from a 30,000 MW control area before and after an ideal $50 \mathrm{MW}$ regulation resource was simulated. While the total $250 \mathrm{MW}$ regulation requirement is only reduced by $50 \mathrm{MW}$ it is clear that the remaining $200 \mathrm{MW}$ of regulation is exercised far less after the $50 \mathrm{MW}$ ideal regulator is deployed. It may be appropriate to pay the ideal regulator more than other slower and less accurate sources of regulation. Clearly more research is required to determine if this speculation is accurate but given the cost of regulation the research is certainly justified.

\subsection{Aluminum Smelting May be Ideal Supplier of Regulation: Basics of Aluminum Smelting}

Aluminum smelting is an electrolytic process that involves the chemical reduction of aluminum oxide into aluminum. The process consumes a great deal of electricity with a typical aluminum smelter consuming hundreds of megawatts. If electric power consumption could be rapidly and accurately controlled without reducing product quality, damaging the process, or excessively impacting productivity, then it might be possible for the aluminum smelter to profitably provide regulation to the power system.

In an ideal system, the full production level of the smelting process could be moved to respond to changing power system needs. Given that smelting systems have been traditionally designed for flat and stable operation at constant power levels, the adaptation of existing assets will require operation inside the unique characteristics of the particular smelter and could require capital upgrades to increase responsiveness. The
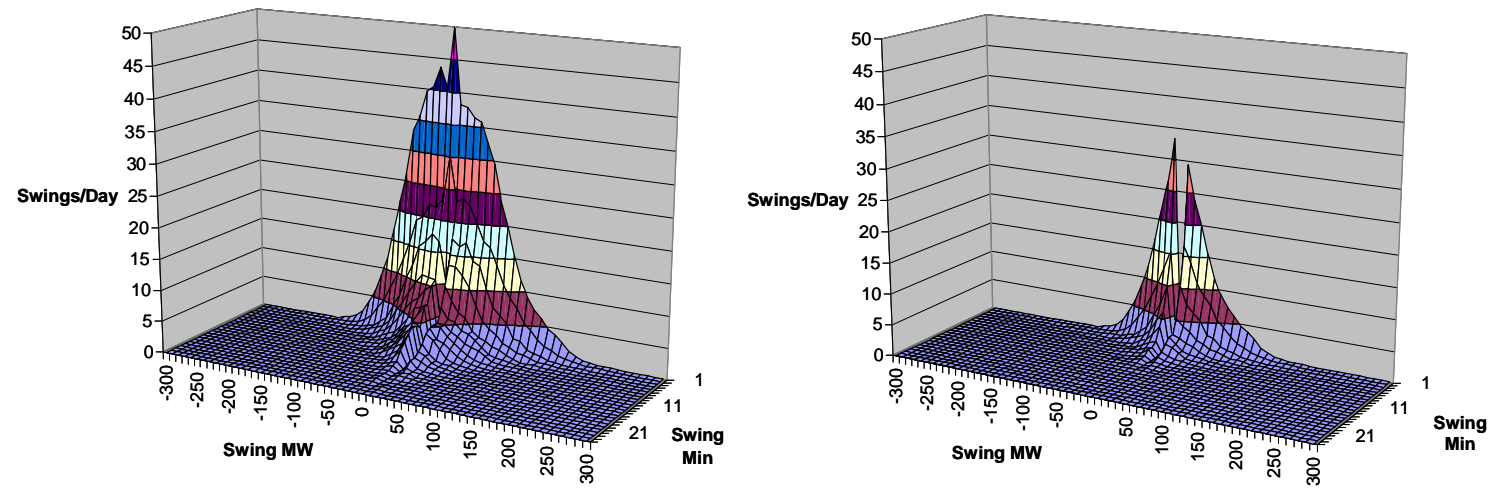

Figure 6. Fifty MW of fast, accurate regulation reduces this Balancing Area regulation burden by more than $20 \%$. 
primary focus of the effort reported on here is to understand whether the smelting process and controls can handle the constantly changing power levels and still operate in a stable manner.

\subsubsection{Aluminum Production Basics}

To determine if supplying regulation is feasible it is first necessary to understand a little about the aluminum smelting process. Very simply, aluminum smelting takes place in "pots" where a DC electric current is passed through a "cryolite" bath containing aluminum oxide and other elements which facilitate the electrolysis. The electric current separates the aluminum from the oxygen and deposits the molten metallic aluminum at the bottom of the pot. Aluminum oxide and electric current are continuously added, aluminum metal is periodically extracted, and electrodes are replaced as they are consumed to keep the process running. Figure 7 provides a simplified aluminum smelting pot schematic. Typically, smelting pots are operated at high direct current (as much as several hundred thousand amps) and very low voltage (often single digit volts). Pots are frequently operated as a connected series load to form a "potline" of hundreds of pots. Total power consumption for a "potline" can be hundreds of MW's and a smelter may have multiple potlines. Potlines are operated continuously and are sensitive to any power interruptions.

Power consumption for each potline is controlled by adjusting the incoming voltage which, in turn, controls the potline current and power consumption within each cell. Each pot is monitored for chemical balance and operation. Individual pots are controlled by adjusting the gap between the carbon anode and the liquid aluminum. The aluminum oxide feed to each pot is also controlled.

Thermal balance is very important to the pot operation. Thermal balance is maintained by controlling the energy input to the pot: the electric power being used to separate the aluminum. Each pot has a large amount of thermal mass with a multi-hour thermal time constant that allows for instantaneous electric power variations that do not greatly impact the pot thermal balance. Average power over a few hours is critical, however.

Thermal balance is important because the pot itself is made of carbon and the molten cryolite bath is corrosive. The pot must be maintained in thermal balance so that the cryolite remains liquid in the center but frozen at the pot walls. The frozen cryolite protects the pot wall from the corrosive molten liquid cryolite. The cryolite can not be allowed to melt all the way to the pot wall or to freeze all the way to the carbon anodes in the center. Melting to the pot wall will corrode the pot. Freezing to the center will destroy the anode and the pot. 

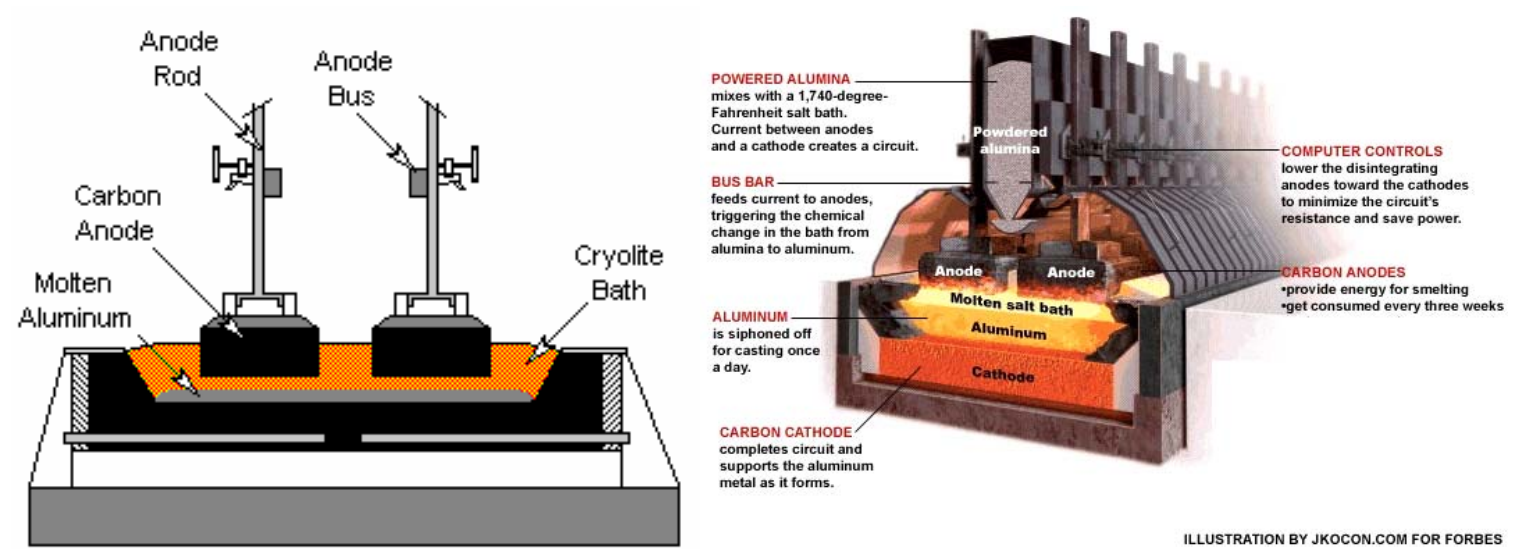

Figure 7 The cryolite bath must remain frozen at the edges to protect the pot wall and molten in the center to protect the anode and the pot itself. (Metals Advisor, 2008 and John Kocon)

Aluminum smelting pots operate at very high temperatures to maintain the aluminum that is produced in a molten metal form. Once production is commenced, it is important that the process be maintained in continuous operation to avoid the loss of electricity and the resulting solidification of cryolite in the pots. Short duration potline interruptions may be tolerated with manageable consequences and related lost metal production. A short potline interruption is in the range of as little as several minutes to no more than three hours (depending upon the condition of the process at the onset as well as the weather outside). The smelting process is very constant in its consumption of electricity, typically operating at 95 percent or greater load factor with little or no perturbation on the electric system, as shown in Figure 8. This is very unlike arc furnaces and large rolling mill motor loads where large load swings are frequent.

Existing smelting plants can provide demand response in two ways. First, as long as the process is stable, small reductions may be achieved by reducing the potline input voltage, thereby reducing electricity consumption. This reduction can be achieved precisely and within seconds. In that case, the production line is not turned off; rather, it is reduced or "turned down." While the reduction can be maintained for some time, a recovery period, i.e. a period of time in which the manufacturing process returns to normal or above normal operation, may be necessary.

The second way a smelter can provide demand response is by turning the entire potline off, thereby reducing consumption of electricity by a larger amount. In that case, the duration of an interruption is more critical and can be sustained only for short periods, depending upon the specific plant limitations. The interruption on a single potline may last from minutes to about two hours. Facilities with multiple potlines can rotate this interruption from line to line, thus enabling a longer total interruption in consumption of electricity. The reduction in consumption of electricity can be achieved in cycles to seconds (upon the opening of a circuit breaker) and will be precise with respect to the amount of the reduction. 


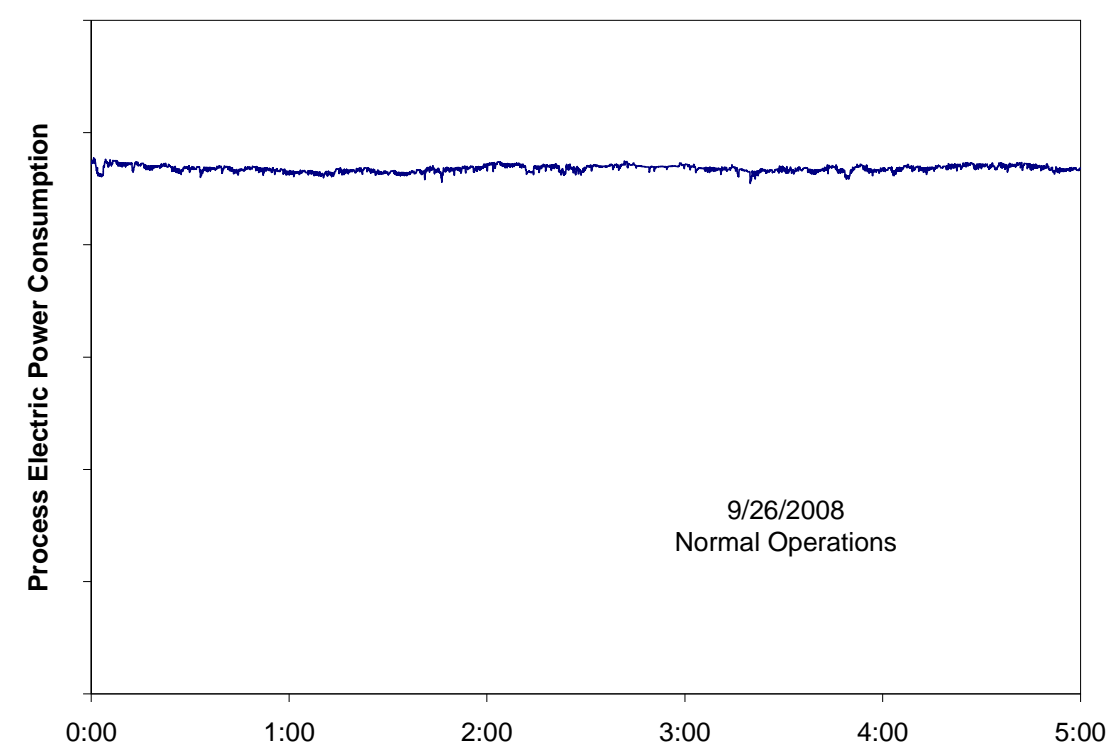

Figure 8 Primary aluminum production typically presents a flat load to the power system.

\subsubsection{Process Interruptions}

While aluminum production power consumption is typically flat, there are times when production must be adjusted, curtailed, or interrupted due to process issues or to perform equipment maintenance. The frequency and necessity of these interruptions is dependent upon the potline design and the specific operating conditions. Some curtailments can be scheduled hours or more in advance, while others only provide a few minutes warning. Although immediate curtailment is infrequently required, these natural process curtailments could theoretically be coordinated with the power system during peak load periods to assist with power system reliability. The most significant element is ensuring that good communication between the aluminum plant and the power system operators is available to avoid dramatic base generation shifts in the power system in response to a very short duration load interruption.

Process interruptions are typically fast and short. Potline power is interrupted by opening a circuit breaker. Power is restored within a few minutes by closing a circuit breaker. These interruptions are required to accommodate process maintenance but they could just as easily be used for power system reliability response. These interruptions closely match power system contingency reserve response (spinning and non-spinning reserve) requirements. 


\subsubsection{Co-optimization of Energy and Ancillary Services}

Co-optimization (also called joint optimization, simultaneous optimization, or rational buying) minimizes the total cost of energy, regulation, and contingency reserves by allowing the ISO to substitute "higher value" services for "lower value" services. (Kirby, 2006B) As long as the ISO has enough spinning and non-spinning reserve capacity to cover contingencies, it will dispatch any remaining resources economically regardless of whether that capacity is labeled as contingency reserve or not. Ancillary service and energy suppliers are automatically co-optimized. Co-optimization has many benefits. It encourages generators to bid in with their actual costs for energy and each of the ancillary services. When they do so the co-optimizer is able to simultaneously minimize overall system costs and maximize individual generator profits.

Unfortunately, current implementation of co-optimization can effectively bar responsive loads as well as most storage devices, emissions-limited generators and water-limited hydro generators from offering to provide ancillary services. ${ }^{2}$ As discussed above, an aluminum smelter might be ideal provider of spinning reserve or regulation, providing faster and more accurate response than generation, but be unable to provide 8,12 , or 24 hour continuous energy response. If there is a risk that the smelter's offer to provide spinning reserve or regulation could be exercised as an energy source (co-optimized) then the smelter would simply not enter the ancillary services market. The power system would be denied the benefit of this excellent reliability resource. Current market rules in New York and New England let the ISOs dispatch capacity assigned to reserves for economic reasons as well as reliability purposes.

Fortunately there is a simple solution. The California ISO had this problem with their rational buyer but changed their market rules and now allows resources to flag themselves as available for contingency response only. PJM allows resources to establish different prices for each service and energy providing a partial solution. ERCOT does not have the problem because most energy is supplied through bilateral arrangements that the ISO is not part of. Energy and ancillary service markets are separate.

\footnotetext{
${ }^{2}$ Some markets are beginning to accommodate storage providing ancillary services by recognizing the stored energy limitations and not co-optimizing storage. Similar accommodations should be made for responsive loads for the same reasons.
} 


\section{MIDWEST ISO ENERGY AND ANCILARY SERVICE MARKETS}

As detailed in the previous sections, there is tremendous motivation for APGI to use the smelter as a demand response resource for both increasing system reliability and for the added financial incentive to reduce overall energy costs through the addition of a revenue stream of providing ancillary services. However, the exact financial benefits, amount of regulation that can be provided, and the rules and regulations for buying and selling of ancillary services are all dependent on the market in any given area. Although Alcoa Inc. has a number of smelter facilities within the United States, this report will focus on the smelter at Warrick Operations. This Warrick facility is located within the Midwest ISO footprint.

\subsection{Market Structure}

Prior to restructuring of electricity markets, electric utilities were vertically integrated, meaning a single electric utility provided the generation, transmission, and distribution infrastructure for the customer. This ensured that each individual utility was responsible for maintaining sufficient reliability as required by different regulation standards and providing enough energy to serve the end user. However, this changed with the adoption of the competitive market structure and the restructuring of the electric utility industry.

Restructuring of the electricity market resulted in the unbundling of competitive generation from regulated transmission. As a consequence, generation facilities that previously provided reliability response as part of their regulated obligation now completely focused on delivering services they were explicitly paid to provide. Reliability became the responsibility of the system operator, but the system operator does not own any generation and can not directly provide reliability balancing services. Ancillary services were defined and markets are in the process of being created to let system operators procure reliability services from competitive generators. The end result is that the responsibility of balancing load and generation shifted to the market. Ultimately, three separate markets were envisioned: one market to pay for the transmission resources, another to pay for the generation, and last a market to ensure that reliability of the power system was adequately maintained through proper balance of generation and load and other supporting services. This vision led to the development of the financial transmission rights (FTR), energy, and ancillary services markets.

\subsubsection{Midwest ISO History}

On February 12, 1996, the transmission owners in the Midwest portion of the United States convened to form the organization known as the Midwest Independent Transmission System Operator (Midwest ISO). The objective of the Midwest ISO was to improve reliability of the Midwest transmission system through coordinated operation of 
the transmission system. An essential element of improving the reliability was to instigate a competitive energy market that would promote healthy competition, send clear pricing signals to motivate production and consumption behaviors and ultimately lower energy prices. Although the Midwest ISO was created in 1996, the opening of the actual energy market did not occur until April of 2005 as testing and approval from FERC were needed to validate the energy market.

Now, the Midwest ISO employs a full-time staff of 728 personnel and is responsible for the delegation of the financial transactions of electrical energy in portions of 15 states in the North-Midwest region of the United States and one Canadian province as shown in Figure 9. This area covers over 920,000 square miles and has 93,000 miles of transmission lines.

Although the region the Midwest ISO governs is formidably large with over 280 participants, the Midwest ISO has still been able to operate under five-minute dispatch. The size of the Midwest ISO has provided for a market peak capacity in excess of $136,000 \mathrm{MW}$.

To monitor the power system network, the Midwest ISO has two control centers situated in Carmel, IN and St. Paul, MN and utilizes a number of tools including: state estimator with real time contingency analysis, power supply monitoring and generation monitoring, delta flow and voltage, flowgate monitoring, alarming and area control error monitors, and interface and frequency monitors. For reliability purposes, Midwest ISO continually refines a network model consisting of 34,336 buses, 253,069 SCADA points, 5,329 generating units, and 28,432 loads.

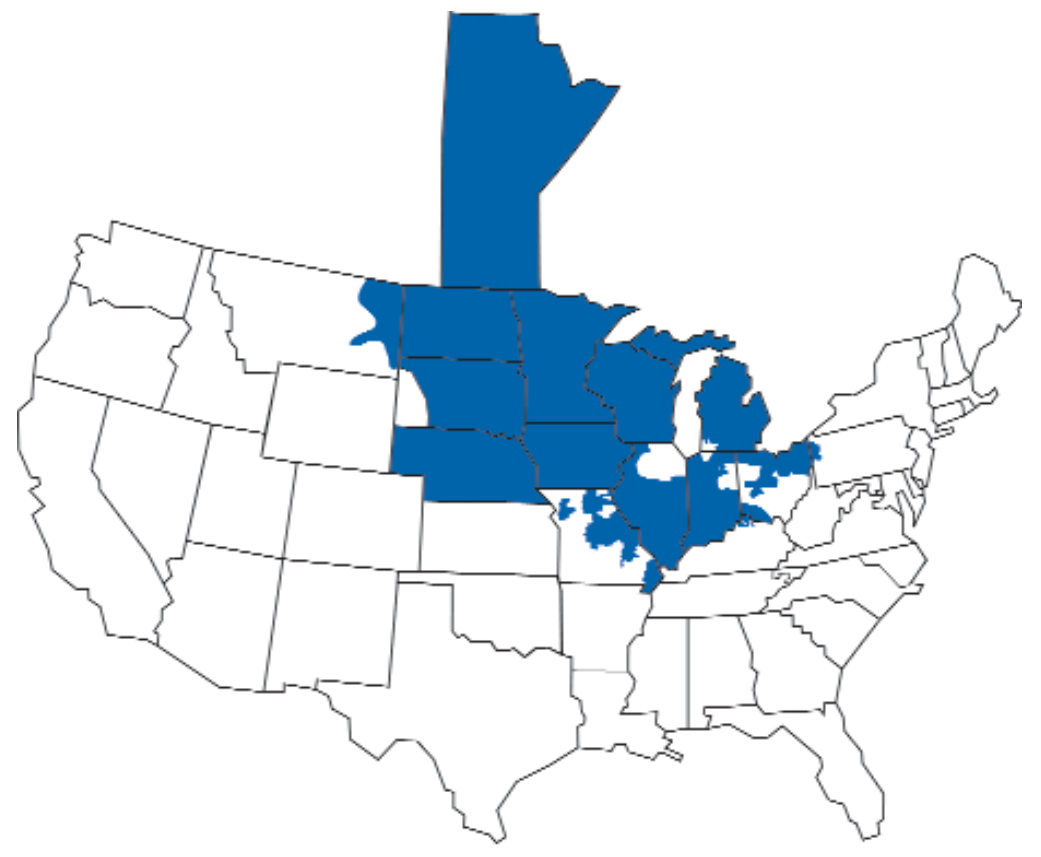

Figure 9 Midwest ISO footprint (www.midwestiso.org) 


\subsubsection{Midwest ISO Energy Market}

In an energy market, the price of energy is driven by supply and demand. Generation companies sell energy to retailers or distribution companies based on the bids placed in the open market. These bids are ranked in price order and the market clearing price (MCP) is determined as shown in Figure 10. Everyone to the left of the MCP completes a transaction in the market. While the MCP is based on a single-bus concept (all generation and loads are located at the same site), the actual price is based on system constraints and location and is provided by the location marginal price (LMP).

In market trading, generation facilities and retailers post buying and selling prices for specific amounts of energy in advance. In the Day-Ahead market, bids are placed a day in advance and are settled by 11:00AM. Based on bidding, a market clearing price is determined. Those generation facilities that offered power at less than the market clearing price sell their power at the market clearing price and those with a buying price exceeding the market price buy the power at the market clearing price. This process is represented in Figure 10. The Midwest ISO energy market clears \$2.6 billion in transactions each month on average.

Of course, during real-time management of power, gaps develop between the load and generation. Faster spot markets, clearing every five minutes, also known as the Real-

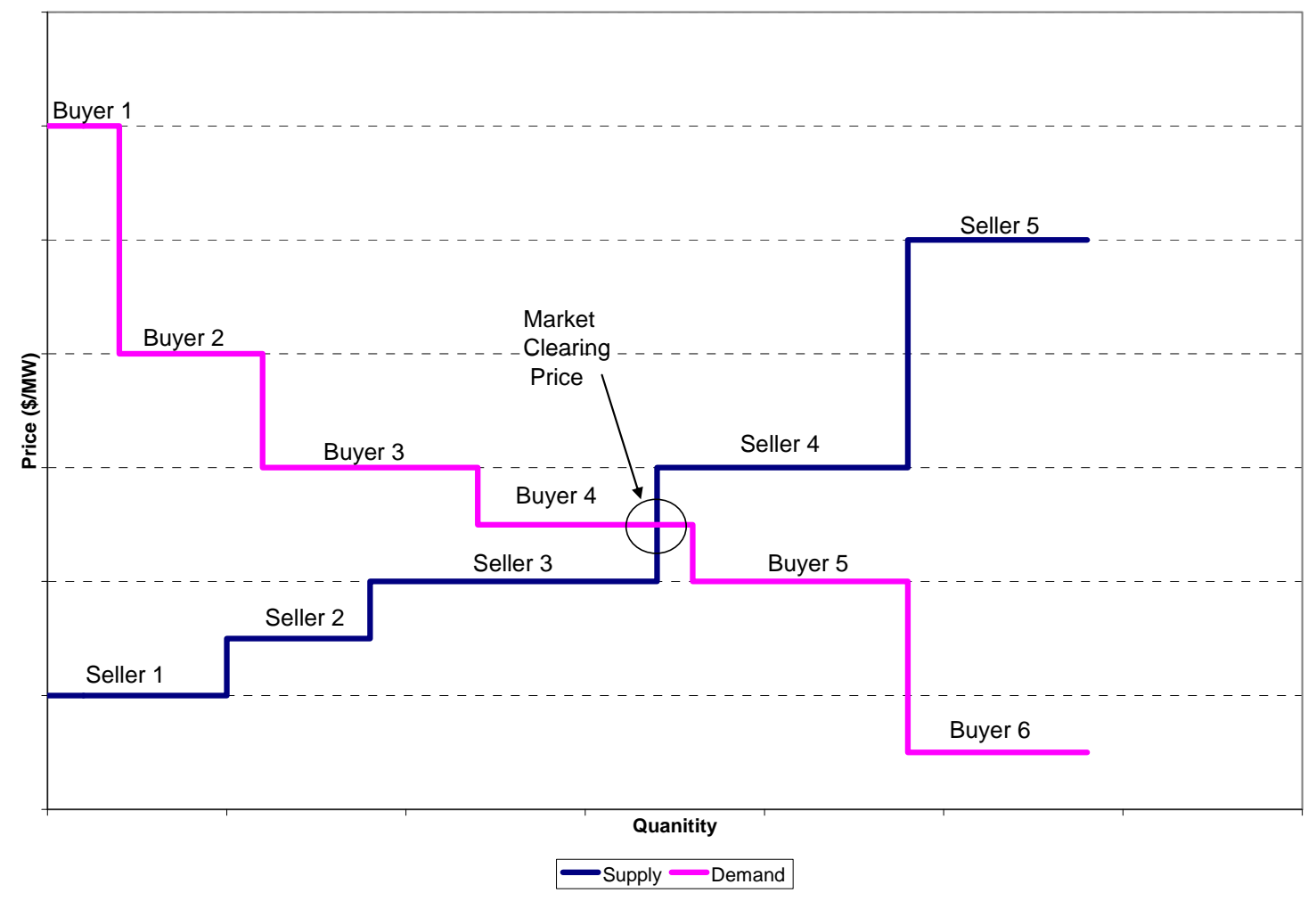

Figure 10 Wholesale Market Supply and Demand. 
Time market, help the system operator balance generation and load. These markets operate similarly to the daily markets, but faster. Generators provide offers to sell. The system operator buys the amount of energy that is required to cover the imbalance between generation and load. Interestingly, system operators can obtain load following from fast energy markets without paying the energy premium associated with regulation. (Kirby and Milligan 2008) Generators with maneuvering capability often find it profitable to respond to the real-time price signal without charging a premium.

\subsubsection{Midwest ISO Ancillary Services Market}

Selling ancillary services represents another large business opportunity for both generation and load. Technical limitations and cost considerations inextricably link the sale of services and the sale of energy. Midwest ISO recognizes that ancillary services are a vital component of a stable and secure power system. Although the Midwest ISO ancillary service market was undergoing testing during the construction of this report, the ancillary service market begin full operation in January 2009. The Midwest ISO has three competitive primary ancillary services: spinning reserve, supplemental reserve, and regulation response services (collectively known as operating reserves). Currently, the Midwest ISO has the services of scheduling and dispatch and reactive supply and voltage control but the first is provided by the balancing authority (BA) and the second is not procured competitively.

The Midwest ISO further splits regulation into two products: regulating reserve and regulation service. Regulation service, defined by the Midwest ISO, is the continuous and automatic adjustment of a resource based on the balancing authority's area control error (ACE). Provision of this service allows the Midwest ISO the ability to maintain system reliability. Regulating reserve is the frequency response of the resource capacity that is held in reserve for the purpose of providing regulation service.

The Midwest ISO categorizes spinning reserve and supplementary reserve as a package known as contingency reserve. As defined in the business practice manual, Midwest ISO expects each category to make up 50\% percent of the contingency reserve. Spinning reserves must begin responding immediately and be fully responsive within ten minutes. Supplementary reserves do not have to begin responding immediately.

\subsection{Midwest ISO Balancing Authorities and Standards}

Generation and load can not be balanced perfectly and there is no need to do so. NERC establishes criteria for how closely the balance must be maintained. Area control error is the primary metric for quantifying generation and load balance. ACE also incorporates interconnection frequency deviation and the balancing area's obligation to help restore frequency. The ACE equation is provided in Table 3. 
The balancing authorities are the agencies in charge of ensuring that generation and load are balanced within a particular area and that the system frequency remains within strict proximity to $60 \mathrm{~Hz}$. The Midwest ISO was composed of 23 balancing areas but the when the market for ancillary services went live, the Midwest ISO assumed the BA authority and become a single BA. Within the Midwest ISO, the previous balancing authorities are listed in Table 2, the organizations that provide oversight over the market rules and regulations include: MRO, RFC, SERC, and SPP.

$\mathrm{ACE}$ is not a directly measured quantity. Instead, the ACE is calculated through knowledge of the deviation between actual and scheduled net flow of energy leaving or entering a balancing area along with frequency deviation from $60 \mathrm{~Hz}$. The standards that

Table 2. Midwest ISO Previous Balancing Authorities.

\begin{tabular}{|c|c|c|c|}
\hline MIDWEST ISO & $\begin{array}{l}\text { MIDWEST } \\
\text { ISO Member }\end{array}$ & & $\begin{array}{l}\text { MIDWEST } \\
\text { ISO Member }\end{array}$ \\
\hline $\begin{array}{l}\text { MRO } \\
\text { Alliant Energy - CA -ALTE } \\
\text { Alliant Energy - CA - ALTW } \\
\text { Dairyland Power Cooperative } \\
\text { Great River Energy } \\
\text { Lincoln Electric System } \\
\text { Madison Gas and Electric Company } \\
\text { MHEB, Transmission Services } \\
\text { MidAmerican Energy Company } \\
\text { Minnesota Power, Inc } \\
\text { Muscatine Power and Water } \\
\text { Nebraska Public Power District } \\
\text { Northern Sates Power Company } \\
\text { Omaha Public Power District } \\
\text { Otter Tail Power Company } \\
\text { SaskPower Grid Control Centre } \\
\text { Southern Minnesota Municipal } \\
\quad \text { Power Agency } \\
\text { Upper Peninsula Power Co. } \\
\text { Western Area Power Administration } \\
\quad \text { - Upper Great Plains East } \\
\text { Wisconsin Public Service } \\
\text { Corporation }\end{array}$ & $\begin{array}{l}\text { Yes } \\
\text { Yes } \\
\text { Yes } \\
\text { Yes } \\
\text { Yes } \\
\text { Yes } \\
\text { Yes }\end{array}$ & $\begin{array}{l}\text { RFC } \\
\text { Cinergy Corporation } \\
\text { City Water Light \& Power } \\
\text { DECA, LLC - Vermillion } \\
\text { First Energy Corp. } \\
\text { Hoosier Energy } \\
\text { Indianapolis Power \& Light } \\
\quad \text { Company } \\
\text { LG\&E Energy Transmission } \\
\quad \text { Services } \\
\text { Michigan Electric Coordinated } \\
\quad \text { Systems } \\
\text { Northern Indiana Public Service } \\
\quad \text { Company } \\
\text { Ohio Valley Electric } \\
\text { Corporation } \\
\text { Southern Indiana Gas \& Electric } \\
\text { Co. } \\
\text { Wisconsin Energy Corporation }\end{array}$ & $\begin{array}{l}\text { Yes } \\
\text { Yes } \\
\text { Yes }\end{array}$ \\
\hline $\begin{array}{l}\text { SERC } \\
\text { Ameren Transmission } \\
\text { Illinois Power Co. } \\
\text { Central Illinois Light Co. } \\
\text { Southern Illinois Power Cooperative } \\
\text { Columbia Water \& Light }\end{array}$ & $\begin{array}{l}\text { Yes } \\
\text { Yes } \\
\text { Yes } \\
\text { Yes } \\
\text { Yes }\end{array}$ & $\begin{array}{l}\text { SPP } \\
\text { Aquila networks - MPS }\end{array}$ & Yes \\
\hline
\end{tabular}

utilize the ACE in calculation include: control performance standard 1 (CPS-1), CPS-2, the balancing authority area control error limit (BAAL), and the disturbance control standard (DCS). 
CPS-1 limits 1 minute average ACE and frequency deviations measured over a year. The resultant calculation is then compared to an acceptable interconnection error limit established for each BA. CPS-2 limits 10 minute average ACE to another BA specific limit. Adequate performance is achieved when CPS-2 is compliant $90 \%$ of the time. The BAAL limit is an alternative to CPS-2 and is founded on 30 minute frequency and ACE deviations. Equations for determining each are shown in Table 3. DCS limits imbalances during contingencies and requires $\mathrm{ACE}$ to be returned to zero or its precontingency value within 15 minutes of the start of the contingency.

CPS-1 and CPS-2 are the historic balancing standards. BAAL, along with its companion Control Performance Measure standard (CPM - identical to CPS-1), is an alternative standard which is being tested in a number of BAs. The Midwest ISO is currently monitoring its CPS-2 performance but operating to the CPS-M and BAAL standards.

Table 3. Area control error standards equations

\begin{tabular}{|c|c|c|}
\hline & Equation & Definitions \\
\hline ACE & $A C E=I_{A}-I_{S}-10 \beta \times \Delta F$ & \multirow[b]{2}{*}{$\begin{array}{l}\mathrm{I}_{\mathrm{A}}=\text { actual interchange } \\
\mathrm{I}_{\mathrm{S}}=\text { scheduled } \\
\text { interchange } \\
\Delta \mathrm{Fi}=\text { frequency } \\
\text { deviation } \\
\varepsilon=\text { acceptable error } \\
\beta=\mathrm{MW} \text { owed by BA for } \\
\text { each } 0.1 \mathrm{~Hz} \text { frequency } \\
\text { away from } 60 \mathrm{~Hz}\end{array}$} \\
\hline CPS1 & $A V G_{\text {aпnиаl }}\left\{\frac{A C E_{i}}{-10 \beta} \Delta F_{i}\right\} \leq \varepsilon^{2}$ & \\
\hline CPS2 & $\left|A C E_{10}\right|=L_{10}$ & $\begin{array}{l}\mathrm{L}_{10}=\text { acceptable } \\
\text { interconnection } \\
\text { frequency error. }\end{array}$ \\
\hline BAAL & $\begin{aligned} B A A L_{\text {Low }} & =\left(-10 B_{i}\left(F T L_{\text {low }}-60\right)\right) \frac{\left(F T L_{\text {low }}-60\right)}{\left(F_{A}-60\right)} \\
B A A L_{\text {High }} & =\left(-10 B_{i}\left(F T L_{\text {High }}-60\right)\right) \frac{\left(F T L_{\text {High }}-60\right)}{\left(F_{A}-60\right)}\end{aligned}$ & $\begin{array}{l}\mathrm{FTL}=\text { frequency trigger } \\
\text { limit }\end{array}$ \\
\hline
\end{tabular}

\subsection{Providing Ancillary Services in the Midwest ISO Ancillary Service Market}


Since the Midwest ISO safeguards system reliability by guaranteeing sufficient reliable services are available, the Midwest ISO must be confident that a resource participating in the ancillary service market can deliver the promised services. Hence, the Midwest ISO has test procedures and strict guidelines that a resource must follow to be eligible to participate in the ancillary services market. Failure to comply with these rules or demonstrate resource capability can lead to disbarment from participation in the Midwest ISO ancillary service market.

\subsubsection{Midwest ISO Classifications of Demand Response Participants}

As responsive loads are extremely diverse and have unique control mechanisms, the Midwest ISO utilizes a classification system that divides those loads that are capable of providing demand response into two categories: Type 1 and Type 2 demand response resources (DRR). The Midwest ISO defines Type 1 DDRs as those resources or load serving entities that have the capacity to be physically interrupted thereby supplying the market with a specific amount of energy or reducing to a specified load point. Hence, if the Midwest ISO determines that system reliability is in question and must shed a load in a specific area, the Midwest ISO sends a signal to this load to be deactivated. Type 1 DDRs have the potential to supply supplemental reserve but cannot provide regulation or spinning reserves.

Type 2 DDRs are implemented via either behind-the meter generation or controllable load resources that have the ability to dynamically respond to the Midwest ISO's dispatch instructions. These resources are significantly more difficult to obtain and consequently are more valuable as they can provide regulation, spinning reserve and supplemental reserves. APGI has registered the controllable portion of the smelting load at Alcoa's Warrick smelter as a controllable load and is currently the only Type 2 DDR registered with the Midwest ISO.

\subsubsection{Required Testing to be Eligible to Participate in ASM of Midwest ISO}

Depending on which ancillary service the resource chooses to provide, regulation or contingency reserves, the Midwest ISO has distinct tests for substantiating the ability of that resource to react to dispatch signals and become a "qualified" resource. This testing process was established in the FERC filed tariff and requires that for a resource to be eligible to supply regulation in the Day-Ahead or Real-Time ASM, a resource must be tested and score $75 \%$ or greater on the regulation performance index (RPI). As shown in Figure 11, the tests involve a four step process in which the resource response is raised

and lowered to the full amount of stipulated regulation and maintained over 5 minute intervals. 


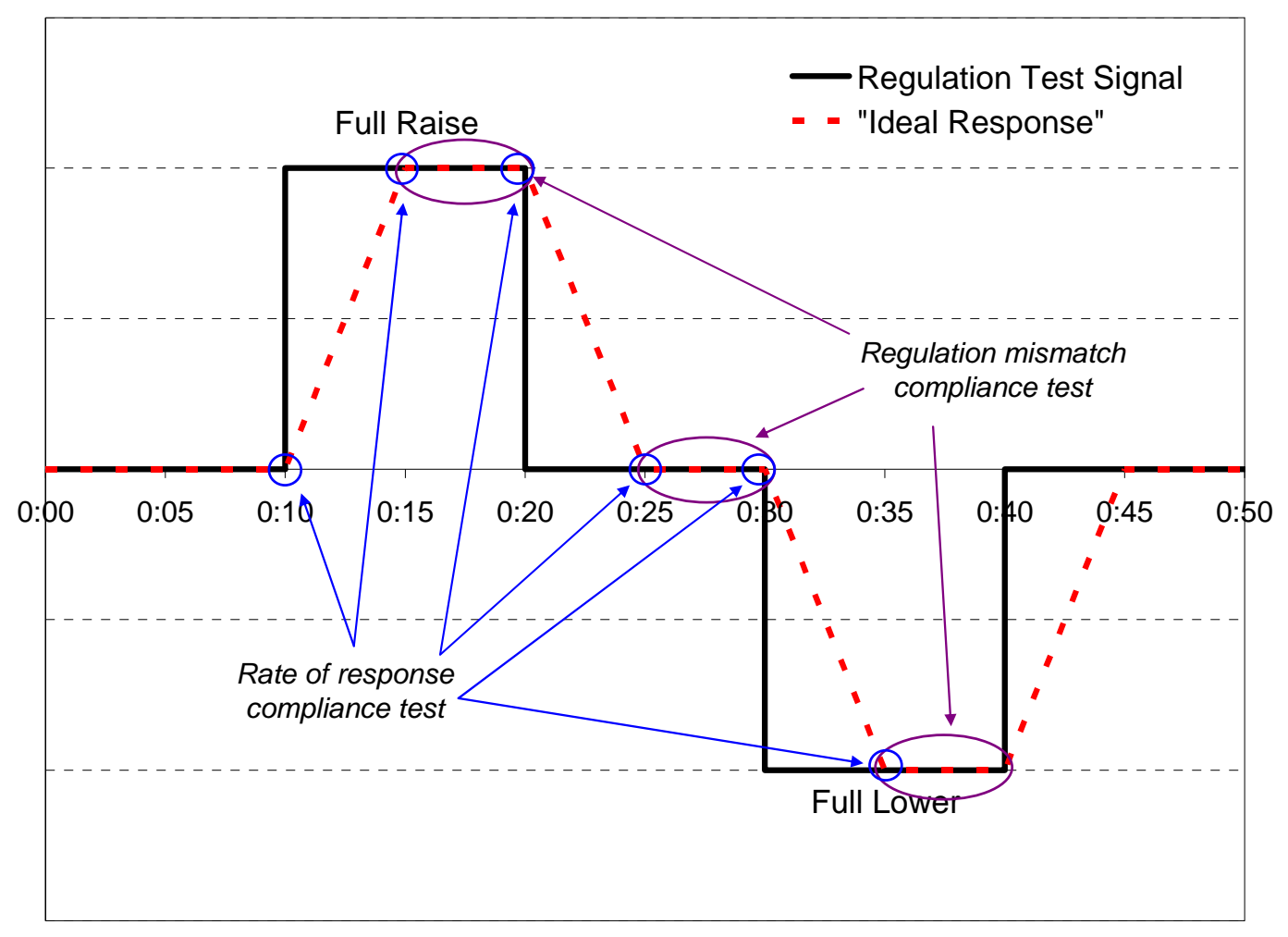

Figure 11 Testing procedure for regulation

Contingency reserve resources must provide at least $95 \%$ of the stated reserve capability during testing.

In conducting these tests, the Midwest ISO will provide the resource a 20 minute notice. For regulation the test lasts for 40 minutes, and the proposed requirements state that a resource only needs to pass the test once a year. Resources that plan to supply contingency reserves only need to demonstrate capability during a 10 minute test but must exhibit capabilities more frequently. Failure to pass the test results in reexaminations. With the second consecutive failure in the regulation performance test, the claimed ramp rate is reduced to the level at which the resource would have passed the regulation performance test. At this point, the resource is now qualified to participate in regulation. For contingency reserve, resources that fail the test must reduce the ramp rate or Real-Tie Maximum Response Limit to match the measured performance.

Interestingly, as the market testing has progressed within the Midwest ISO, it was believed that many existing resources that are currently supplying regulation and contingency reserves would not be able to pass the qualification test. Therefore, the Midwest ISO has suspended the requirement for existing generators and grand fathered existing resources. 


\subsubsection{Requirements on Resources that are involved in ASM of Midwest ISO}

Once a resource has displayed the capability to provide an ancillary service through testing, the resource may participate in the market. Nevertheless, the resource must still follow a set of rules to continue to be eligible to participate. Depending on the market (Day-Ahead or Real-Time) and the type of service provided (regulation, spinning reserve, or supplemental reserve) a diverse set of rules has been constructed, as shown in Table 4 and Table 5. Resources must be physically located within the Midwest ISO balancing authority or be pseudo-tied into the Midwest ISO balancing authority. There is a $1 \mathrm{MW}$ minimum size requirement for providing ancillary services.

\subsubsection{Associated Penalties for Not Performing}

Resources that participate in the market, but fall short of supplying the actual amount of energy or ancillary service requested force the system operator to locate other resources through the market. For regulation services, the Midwest ISO constructs a tolerance band equal to $+/-4 \%$ of the sum of the average energy dispatch targets and regulation deployments with a minimum of $+/-6 \mathrm{MW}$ and a maximum of $+/-20 \mathrm{MW}$. If a resource exceeds the tolerance band for 3 consecutive 5-min intervals, a Failure to Follow Dispatch Flag (FFDF) is set. A flagged resource must pay back the DA award for

Table 4. Regulation resource requirements

\begin{tabular}{|c|c|c|}
\hline MIDWEST ISO Requirement & Day-Ahead & Real-Time \\
\hline Procurement & \multicolumn{2}{|c|}{$\begin{array}{l}\text { - MIDWEST ISO buys regulation in both the Day-Ahead and } \\
\text { Real-time market }\end{array}$} \\
\hline Capability & \multicolumn{2}{|c|}{$\begin{array}{l}\text { - The resource must be fully deployable in both the regulation-up } \\
\text { and regulation-down directions within five minutes. }\end{array}$} \\
\hline Control & \multicolumn{2}{|c|}{$\begin{array}{l}\text { - The resource must be capable of automatically responding to } \\
\text { frequency deviations. } \\
\text { - The resource must utilize a speed governor or similar device } \\
\text { with a deadband and droop characteristic } \\
\text { - The resource must follow ERO standards for frequency } \\
\text { responsive resources. }\end{array}$} \\
\hline Communication & \multicolumn{2}{|c|}{$\begin{array}{l}\text { - The resource must be capable of receiving and responding to } 4 \\
\text { second AGC commands } \\
\text { - The resource must provide telemetered data that can be scannec } \\
\text { every } 2 \text { sec. }\end{array}$} \\
\hline Duration & \multicolumn{2}{|c|}{$\begin{array}{l}\text { - The resource must be capable of supplying regulation for a } \\
\text { continuous duration of } 60 \text { mins. }\end{array}$} \\
\hline \multirow[t]{2}{*}{ Eligibility } & $\begin{array}{l}\text { Committed internal market } \\
\text { and committed external } \\
\text { pseudo-tied market } \\
\text { generation resources } \\
\text { - } \quad \text { committed type 2 DRR }\end{array}$ & $\begin{array}{l}\text { On-line and Synchronozied } \\
\text { Internal Market Generation, } \\
\text { External Pseudo-tied market } \\
\text { generation, and Type } 2 \text { DRR }\end{array}$ \\
\hline & - available external asynchron & us resources \\
\hline
\end{tabular}


Table 5. Contingency reserve requirements (Spinning and Supplemental)

\begin{tabular}{|c|c|c|}
\hline & Day-Ahead & Real-Time \\
\hline MIDWEST ISO Definition & \multicolumn{2}{|c|}{$\begin{array}{l}\text { - Contingency reserve is unloaded resource capacity set aside on } \\
\text { an hourly basis to be available to offset abnormal supply } \\
\text { deficiencies }\end{array}$} \\
\hline Capability & \multicolumn{2}{|c|}{ - The resource must be fully deployable within the 10 minutes } \\
\hline Control & \multicolumn{2}{|c|}{$\begin{array}{l}\text { - The resource must be capable of automatically respond to } \\
\text { frequency deviations. } \\
\text { - The resource must utilize a speed governor or similar device } \\
\text { with a deadband and droop characteristic } \\
\text { - The resource must follow ERO standards for frequency } \\
\text { responsive resources }\end{array}$} \\
\hline Communication & \multicolumn{2}{|c|}{$\begin{array}{l}\text { - The resource must provide telemetered data that can be scanned } \\
\text { every } 10 \mathrm{sec} \text {. }\end{array}$} \\
\hline Duration & \multicolumn{2}{|c|}{$\begin{array}{l}\text { - The resource must be capable of deploying } 100 \% \text { of their } \\
\text { cleared contingency reserve for } 60 \text { minutes. }\end{array}$} \\
\hline \multirow[t]{2}{*}{ Eligibility (Spinning) } & \multicolumn{2}{|c|}{$\begin{array}{l}\text { - Type } 1 \text { DDR if no minimum frequency responsive contingency } \\
\text { reserve ERO standard exists } \\
\text { - Available external asynchronous resources }\end{array}$} \\
\hline & $\begin{array}{l}\text { - Committed internal market } \\
\text { and external pseudo-tied } \\
\text { market generation resources } \\
\text { - Committed type } 2 \text { DRR }\end{array}$ & $\begin{array}{ll}- & \text { Online and } \\
\text { Synchronized Internal } \\
\text { market and External } \\
\text { Pseudo-tied market } \\
\text { generation resources } \\
\text { - Online and synchronized } \\
\text { type 2 DRR. }\end{array}$ \\
\hline Eligibility (Supplemental) & $\begin{array}{l}\text { - Uncommitted quick-start } \\
\text { internal market and external } \\
\text { pseudo-tied market } \\
\text { generation resources } \\
\text { - Uncommitted Type } 2 \\
\text { Resources }\end{array}$ & $\begin{array}{l}\text { - Available quick-start } \\
\text { internal market and external } \\
\text { pseudo-tied market } \\
\text { generation resources } \\
\text { Available offline Type } 2 \\
\text { Resources }\end{array}$ \\
\hline
\end{tabular}

regulation to the Midwest ISO. Additionally, the resource misses the opportunity to sell regulation services in the Real-Time market. Further, a penalty is assessed which is based on the MW output of resources multiplied by a regulation charge modifier. The regulation charge modifier is derived from the additional cost of providing regulation from high priced resources.

A different method of determining compliance is utilized for spinning reserve. When the Midwest ISO dispatches a resource to provide spinning reserve, they record the MW output of the resource and begin a 10-min timer. At the end of the 10-min period, the Midwest ISO records the new MW output of the resource. If the resource fails to provide the deployed amount of energy, the resource's Contingency Reserve Failure Flag (CRFF) is set. When the CRFF is set, the resource must purchase megawatts equal to their shortfall at Real-Time prices. Further, the Real-Time awards for contingency reserves for the rest of the day are capped at the MW reserve level that was successfully deployed. 
Each failing of a resource in meeting the required obligations threatens the reliability of the power system. Therefore, many system operators, including the Midwest ISO, will disbar resources from participation with continued failings in meeting the committed demand.

\subsection{Comparison with Other Markets}

Hourly markets exist in several regions for up to five ancillary services: regulation (up and down in some markets), spinning reserve, non-spinning reserve, and replacement reserve. In each of these regions, regulation is always the most expensive ancillary service followed by spinning reserve, non-spinning reserve, and replacement reserve. Some markets split regulation into regulation up and regulation down. This distinction is semantic rather than technical. Regulation prices in split markets can be compared with combined markets simply by adding the up and down prices.

Hourly ancillary service market price data is available since September 2000 for California, since October 2001 for New York, and since April 2003 for ERCOT. Monthly averages of hourly prices for regulation and energy are shown in Figure 12. Total regulation prices (regulation up plus regulation down) are shown for California and

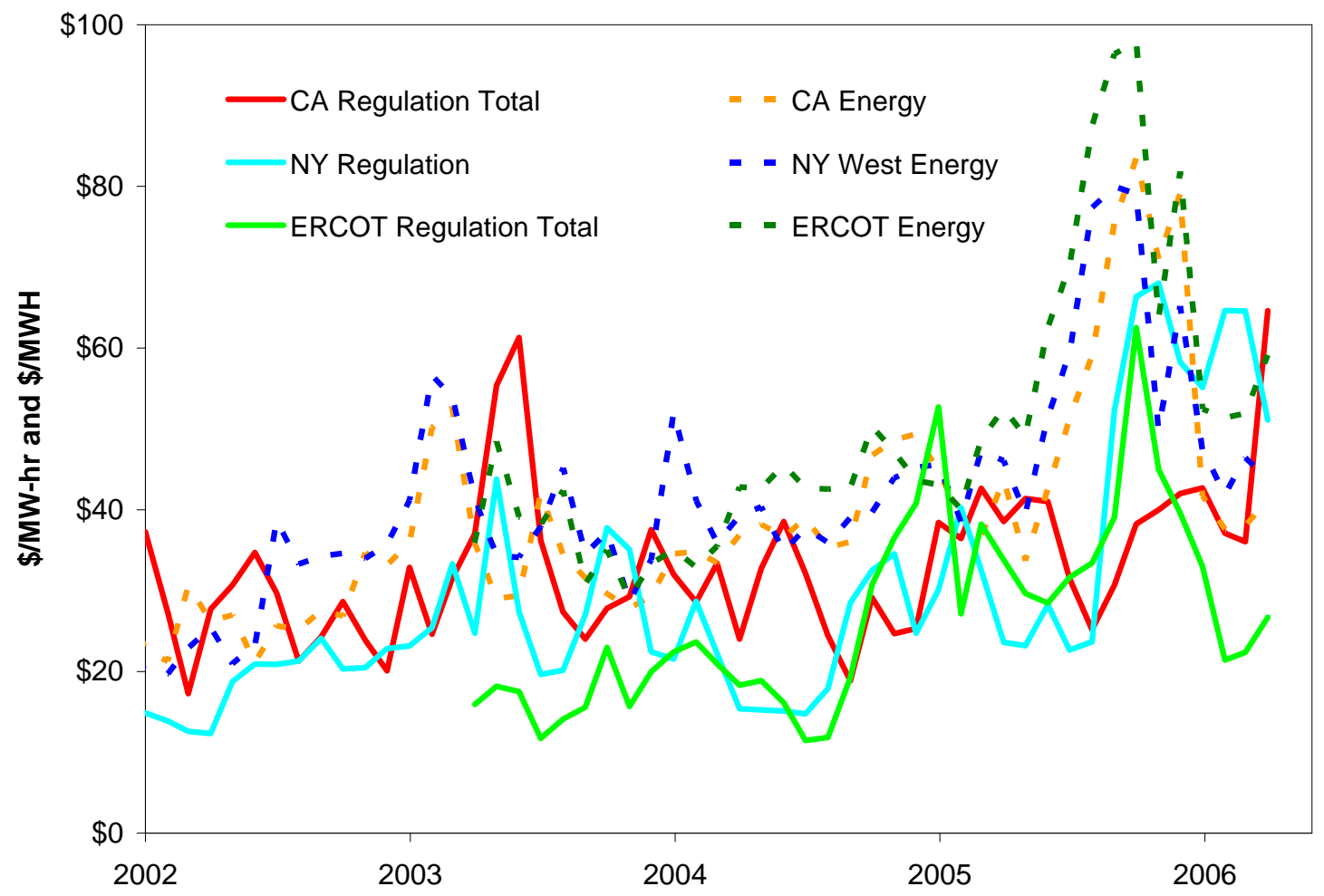

Figure 12 Monthly average regulation prices are typically (but not always) somewhat lower than energy prices. 
ERCOT to make them comparable to the New York regulation product which is a combined up and down service.

Figure 12 shows that regulation prices, which include no fuel or energy component, are in the same range as real-time energy prices and are at times higher. Also, both energy and regulation prices are volatile, even on a monthly average basis. Regulation price also tends to track energy price, because of the lost opportunity cost.

Figure 13 compares all of the ancillary services on a monthly average price basis. Again, prices are volatile but over the 3.5 years regulation is always significantly more expensive than spinning reserve which is more expensive than non-spinning reserve and replacement reserve. These results are expected to be mirrored by the Midwest ISO energy and ancillary service markets. Therefore, it is in the best interest of a resource to be able to provide regulation over the other ancillary services.

Table 6 contains the annual average and maximum costs for the various ancillary services in the California, ERCOT, and NY markets. In 2008, the average price for regulation in these markets ranged from $\$ 59.50 / \mathrm{MW}-\mathrm{h}$ down to $\$ 33.40 / \mathrm{MW}-\mathrm{h}$. Regulation is consistently the highest priced ancillary service in all regions and all years.

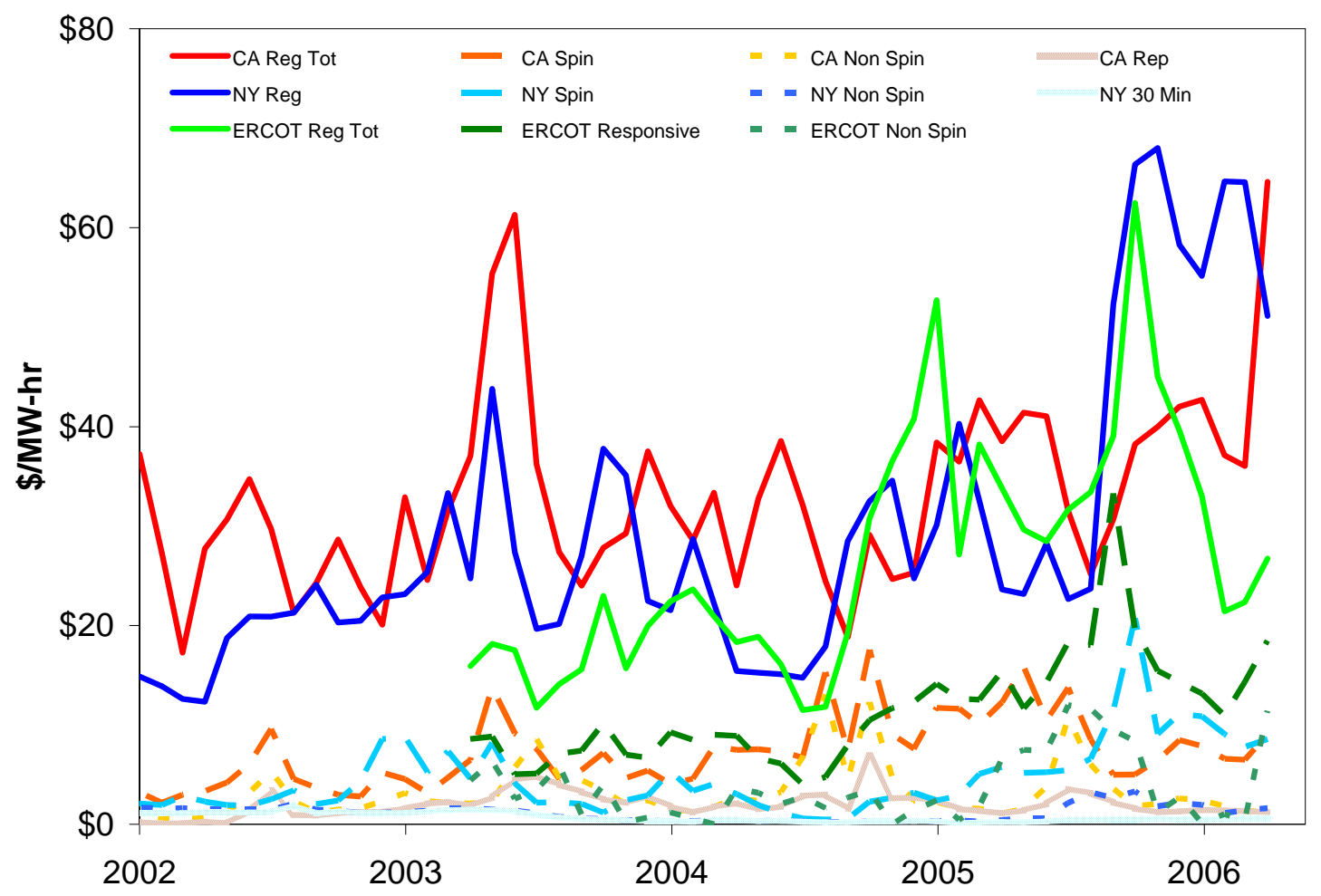

Figure 13 Ancillary service prices in all markets follow a pattern where regulation is most expensive and replacement reserve is least expensive. 
Table 6 Annual average and maximum ancillary service prices from four markets for seven years.

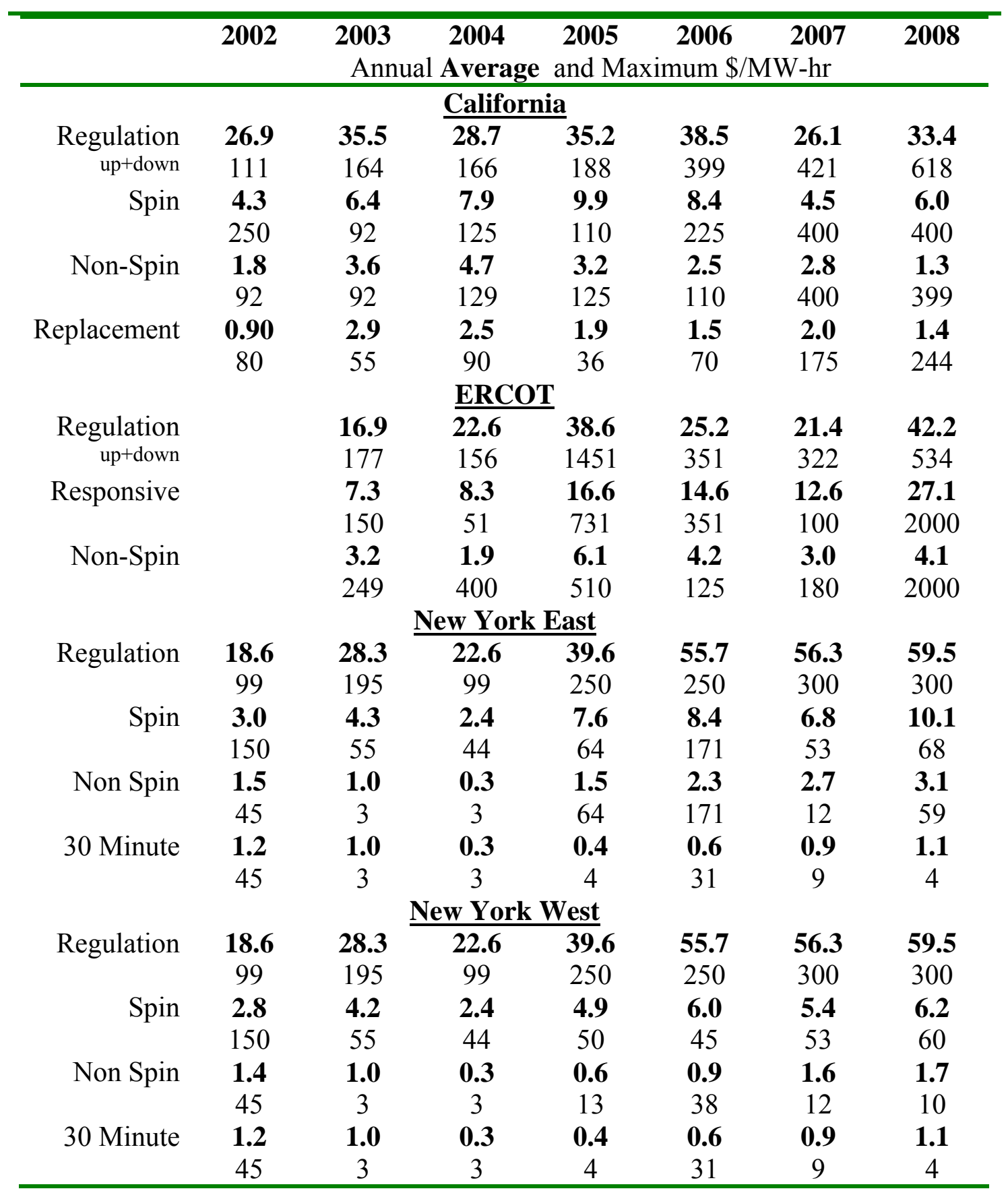




\section{OPPORTUNITIES AT WARRICK}

Although Alcoa has other aluminum related manufacturing and production facilities in the U.S., Warrick is the only one that is fully integrated, with both generation and aluminum production at the same site. The massive facility with 120 acres under roof and an 8,300 acre plant site, was constructed in 1960 near Evansville, IN.

With generation, load, and a transmission interconnection, Warrick has the ability to both buy and sell energy in the Midwest ISO market. The buying and selling of energy is dependant on the relative costs of Warrick generation, Midwest ISO energy, and the realtime value of aluminum production. Energy transactions present an economic optimization challenge in themselves and Warrick operators have become adept participants in the Midwest ISO energy markets. This electric market experience provided a good basis for considering the supply of regulation services.

\subsection{The Shift in Warrick Operations}

The start of the Midwest ISO Real-Time energy market in 2005, created a significant paradigm shift in the Warrick operational methodology and presented new economic opportunities:

- The ability to purchase power at cost less than the internal cost to produce electricity.

- The ability to balance purchase power strategies through the bilateral agreements and day ahead and real time markets during periods when onsite generation was not available

- The opportunity to balance the cost of aluminum production with market prices to reduce demand and either sell excess power or reduce purchase power.

These opportunities have had significant impacts on the Warrick facility as the economic decision has become either to produce aluminum or sell internally generated power. As a price taker in the Midwest ISO energy market, Warrick Operations already participates in price responsive demand and generation reductions. These have become a normal part of the business, with load shaves and generation reductions occurring on a daily basis. In 2007, APGI documented over 1800 responses to Midwest ISO market conditions.

Nevertheless, these mechanisms only serve as measures that partially mitigate increasing costs. Furthermore, the core business of Warrick Operations is the production of aluminum. Once the benefits of selling energy outweigh the profit of aluminum, the viability of the aluminum production will come into question. 


\subsection{Warrick Generation}

The APGI facility at Warrick has four B\&W coal fired generating units on site with a combined capacity of $732 \mathrm{MW}$ and $908 \mathrm{MVA}$, well above the $470 \mathrm{MW}$ total aluminum plant load. Three of the generators are rated at $144 \mathrm{MW}$ and $176 \mathrm{MVA}$. The fourth is rated at $300 \mathrm{MW}$ and $380 \mathrm{MVA}$. Unit 4 is jointly owned with the local utility company, Vectren. APGI's entitlement of Unit 4 capacity is 150 MW's. APGI operates all of the units and has the right to use any excess Unit 4 capacity that is available. The plant consumes $2.8 \mathrm{~mm}$ tons of coal annually. Emissions have been significantly reduced as a result of a major investment in emissions control upgrades. Warrick generation is both economic for aluminum production and very competitive in the Midwest ISO energy market.

These generation assets are identified within the Midwest ISO footprint as "behind the meter generation". The turbine generators do not have the opportunity to sell power into the day ahead market. It is significant to note that the generation assets at Warrick do not have the capability of providing ancillary services into the market and all response from the facility is being performed directly from the smelting load.

\subsection{Warrick Transmission and Electrical System}

The Warrick facility interconnects to the Midwest ISO electric system and interconnection in the local power grid of Southern Indiana. While initially designed principally to connect the generators directly to the potlines the substation arrangement provides a great deal of flexibility for both the load and the generation to interact with the Midwest ISO market through the transmission lines. There is not, however, sufficient transmission capacity to either move all of the generation to market or to fully supply the plant load from the Midwest ISO market. Still, there is ample transmission capacity to trade vigorously in the energy and regulation markets.

\subsection{Warrick Smelter Capabilities}

The smelting process is very constant in its use of electricity, typically operating at 98 percent or greater load factor with little or no perturbation on the electric system as shown in Figure 8. This is very unlike arc furnaces and large rolling mill motor loads. The total load encompassed by the smelting process is approximately $500 \mathrm{MW}$ 's and the total load for the facility is currently around $550 \mathrm{MW}$ 's.

The Warrick facility has multiple potlines with over a hundred individual pots each. Potline current can be controlled over a range while maintaining acceptable pot conditions. Rectifiers convert the AC voltage to various DC voltages which also controls

potline current. Because the rectifier uses a mechanical tap changer to adjust the power to the potline, the resolution of power adjustment at Warrick is between .7 MW's and 1.2 MW's per step, depending upon which of the potlines is being utilized for load changes. 
Historic potline control systems have focused on maintaining even heat balance on pots. In order to participate in the demand response process, the control logic was modified to target specific MW levels, rather than amp hours into the pot.

\subsection{System Capability}

APGI operates as a Load Serving Entity (LSE) within the Midwest ISO to supply the power needs of the aluminum smelter at Warrick operations. Although APGI is a FERC regulated public utility, APGI does not have the same balancing responsibilities and contracts as the local public utility. APGI does a manual balancing of load and generation assets through their control room operators who manually adjust generation levels at the turbine generators and procures any energy imbalance directly from the market with excess consumption being purchased and excess production being sold at the real time market price.

At the start of this project, no system existed for the automatic control of potline power levels. The process for power reductions started with a phone call from APGI to the potline supervisor that requested a load reduction at the Alcoa Warrick smelter. The shift supervisor would initiate amp target reductions on the potlines until the desired load reduction was achieved. When the decision was made to eliminate the line shave (to restore the power level), another call is made and the supervisor adjusts the line to normal power levels. A similar process is used to operate at power levels above the normal operating limits (i.e. during periods of very cheap power or to make up production).

While this manual process is sufficient for participation as a price responsive load, it does not meet the requirements for supplying services like regulation and spinning reserves, which have the largest value to Alcoa. The most significant implementation piece of this project has been establishing an automated control system for accepting and responding to MW target values while maintaining a stable potline operation: essentially AGC for the aluminum smelter load.

Similarly, APGI did not have the instantaneous and automated communications systems required for constant interface with the Midwest ISO when providing market services to the grid. 


\section{PROVIDING REGULATION AT WARRICK}

Although providing regulation services is conceptually simple, implementation is much more complex. New equipment was necessary for communication and control of the process and has required extensive tuning to reach sustained reliable operation. Employees had to be trained to both operate this equipment and manage the impact to the process when power levels are adjusted in response to power system needs. APGI also had to develop a control hierarchy that determines how and when regulation should be performed based on facility limitations and an economic schedule. Finally, during testing, APGI must evaluate the effect of providing regulation on aluminum production efficiency and emissions.

APGI's testing of the Warrick plant's capability to provide regulation was coincident with the Midwest ISO's testing of its new ancillary service markets. The Midwest ISO conducted over 39 operational tests where the Midwest ISO operated as a single BA, taking control from the individual members and working through multi-hour operational tests where the Midwest ISO controlled generation and demand response resources. During these tests, the Midwest ISO simultaneously operated Security Constrained Unit Commitments (SCUC), Security Constrained Economic Dispatch (SCED), and the energy and ancillary services markets under the proposed market rules while ensuring that all applicable reliability requirements were met as a centralized balancing authority. Warrick has been participating in the Midwest ISO tests since June 11, 2008. Regular testing began on August 28, 2008.

\subsection{Plant Modifications}

Two primary systems were designed and installed to facilitate market participation; the Power Plant Energy Management System (EMS) and the Smelter Potline Load Control System (LCPD). Metering, monitoring, communications and control systems at the aluminum plant had to be modified to provide fast and accurate power consumption control. Hardware and software had to be implemented for the Warrick plant to communicate with the Midwest ISO and participate in the Midwest ISO ancillary services market. Employees had to receive training to handle the new hardware and software and also manage the provision of the ancillary services. Lastly, a method had to be found that would transform the demand response capability of the Warrick load into a format that the new Midwest ISO ancillary service market could recognize as a regulation provider: basically the load had to be made to look like a generator. The total cost of the modifications to the plant is in excess of $\$ 750,000$ and now includes ongoing maintenance and operation costs and additional costs that are incurred with evolving changes as the Midwest ISO refines the ancillary services market process. 


\subsubsection{Bidding a Load Into The Midwest ISO Regulation Market}

Regulation is a control or capacity service that contains no energy. An ideal regulation resource might be a storage device that sometimes injects power into the grid and sometimes withdraws power, always at the system operator's command, with zero net energy. Neither generators nor loads behave this way, however, and storage for regulation is still only experimental. ${ }^{3}$ More importantly for Warrick, the Midwest ISO rules and software do not recognize schedules that can swing plus and minus. The Midwest ISO requires a regulation schedule that is either all load or all generation. Working through an example should help explain the importance of this restriction.

Suppose a Market Participant has a mean load of approximately 500 MW's which satisfies normal operational limits and is covered through 500 MW's of behind the meter generation (similar to Alcoa's Warrick facility). To provide 15 MW's of regulation a controllable load resource would have to swing \pm 15 MW's from the $500 \mathrm{MW}$ mean. Peak load would be 515 MW's and minimum load would be 485 MW's as shown in Figure 14.

Ideally, to provide $15 \mathrm{MW}$ of regulation, the load would set its generation at $500 \mathrm{MW}$ to meet the expected average load. There would be a $0 \mathrm{MW}$ energy schedule with the Midwest ISO. The Midwest ISO would control the plant between $485 \mathrm{MW}$ and 515 MW. The resource would be paid for $15 \mathrm{MW}$ of regulation and would settle any net energy difference either buying energy if the Midwest ISO controlled the load up or selling energy if the Midwest ISO controlled the load down.

In practice, the resource must set its generation at $484 \mathrm{MW}$ and supply $484 \mathrm{MW}$ of its load. The resource would then purchase energy from the Midwest ISO market and give the Midwest ISO control of that purchase power schedule. The actual amount of energy purchased would be $31 \mathrm{MW}$ 's. The resource then self schedules $16 \mathrm{MW}$ 's back into the market so that the minimum resource load would be $1 \mathrm{MW}$ and the maximum resource load would be $31 \mathrm{MW}$ (with $16 \mathrm{MW}$ energy scheduled back into the market with \pm 15 MW regulation). The resource would then be able to sell $16 \mathrm{MW}$ from its behind the meter generation into the Midwest ISO market and thus offset the purchased energy. The facility could also sell any other energy that it either thought that the Midwest ISO might hold the plant above or below the $500 \mathrm{MW}$ point or if it thought the Midwest ISO energy price was attractive. A facility such as the one described would increase it's bids, metering and settlements from a single node to four nodes requiring that four separate bids be uploaded each day. Additionally, four separate meter data sets must be analyzed and uploaded, four separate load forecasts must be developed and the settlement statements must be individually analyzed at each of the four nodes. All of this accounting gets to the same place in the end but it adds unnecessary complications to the

\footnotetext{
${ }^{3}$ Beacon Power is experimenting with flywheel storage for regulation. Pilot projects are being conducted in California and New York. Beacon's latest offering at the time of this report's publication is $\pm 20 \mathrm{MW}$ storage facility. Storage has the same scheduling difficulty that Warrick experiences. Both MISO and the New York ISO are accommodating storage with special market rules that may be appropriate for responsive load.
} 
resources daily scheduling process and illustrates some of the barriers that are created for participating in the market.

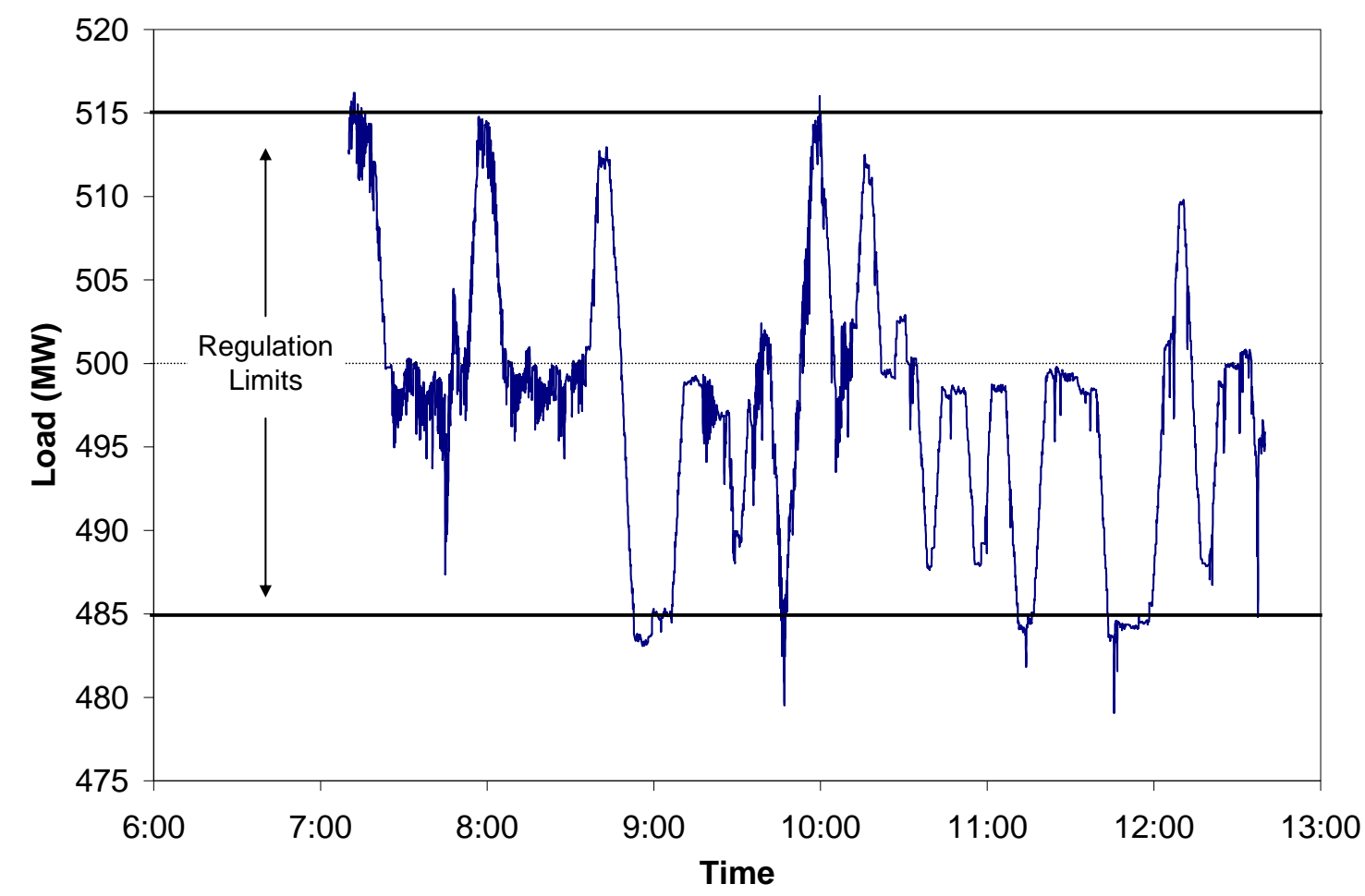

Figure 14 Example of regulation in the Midwest ISO Ancillary Services Market tests.

\subsubsection{Communication and Metering}

To provide regulation in the ancillary service market, the Midwest ISO requires that a resource be able to follow the provided regulation signals. As a result, in an effort to make the system autonomous, APGI had to install a communication and control system that would take the Midwest ISO signal, process the signal, and perform adjustment of the potlines to follow the provided signal. This system is shown in Figure 15.

Since the Midwest ISO operates a Day Ahead and Real Time market, the availability of capacity resources are bid into the Day Ahead market. This gives a schedule for services to be available during the Real Time. After the Midwest ISO ancillary service market clears, Midwest ISO sends APGI a signal containing the maximum limits of regulation 


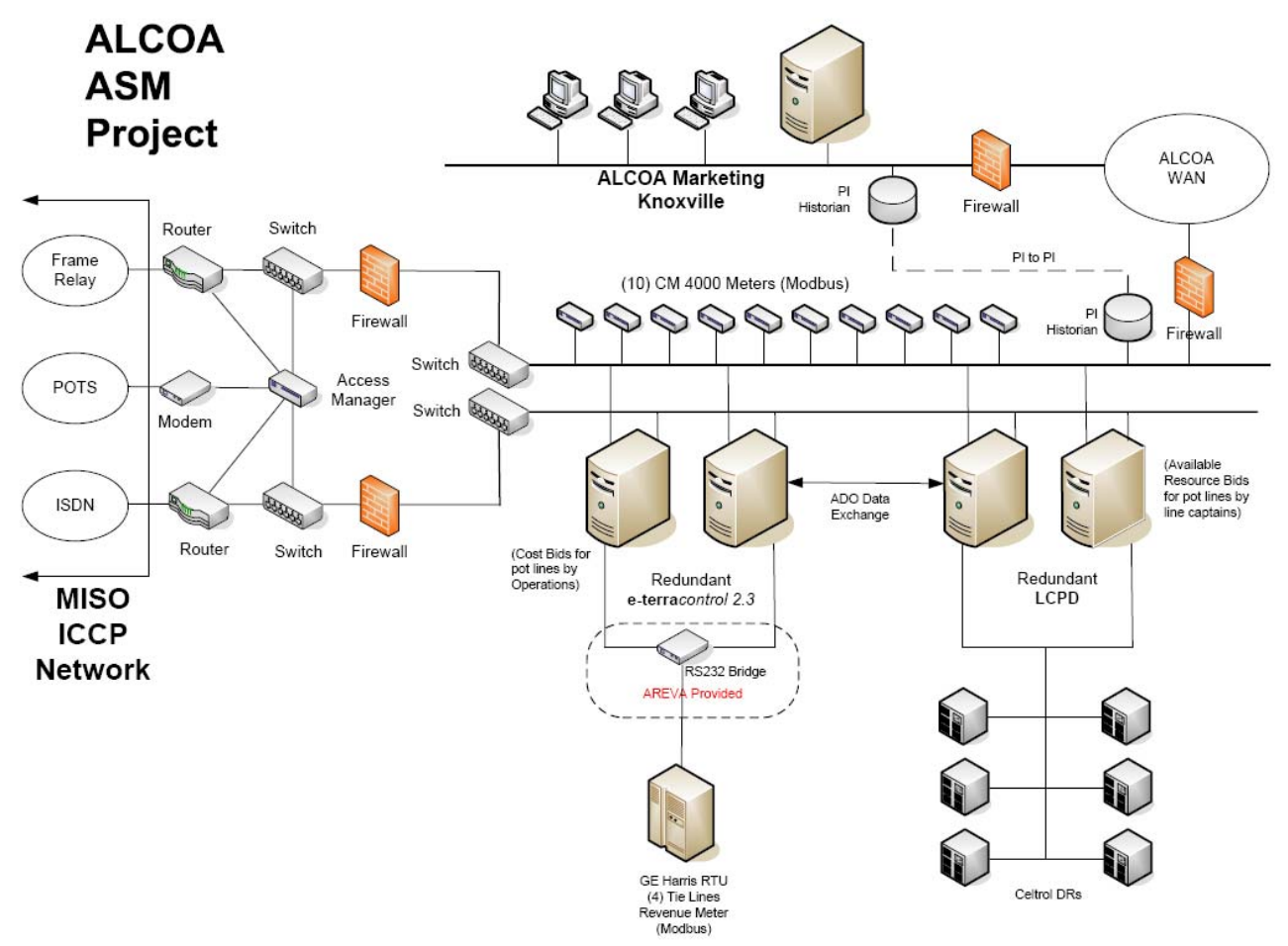

Figure 15 Energy Management System

and the amount cleared for each hour. APGI utilizes a customized software system to determine the total load that the smelter should provide based on the amount of regulation required. This amount is communicated to the smelter.

Verification that APGI is performing the correct amount of regulation is done through CM 4000 meters that measure the actual load and send the data to Midwest ISO every 2 seconds. The regulation signal is sent to APGI every 4 seconds. Midwest ISO compares the expected and actual regulation response.

To guarantee that the communication between the Midwest ISO and APGI is available, three separate methods are used: T1 (high speed internet), ISDN (integrated service digital network, integrates speech and data on same telephone line), and telephone. APGI also utilizes a PI Historian that records all of the relevant electrical parameters for future analysis.

\subsubsection{Employees}

Along with providing hardware and software installations for communication and metering, it became necessary for APGI to become involved with the various Midwest ISO working groups that developed the market design and operating procedures. Plant personnel attended work shops and seminars to obtain better understanding of the Midwest ISO market structure and rules. Further training became necessary with the 
adoption of the computer system for the EMS system and PI Historian. Finally, as participation in the ancillary service market requires a continual obligation to match the signal provided by Midwest ISO and evaluate the opportunity costs of providing regulation, and more significantly, an increase from a single load registration that is bid and settled against to three separate nodes that must each have daily bids and offers, plus a daily settlement review; a new staff person was required to manage these expanding responsibilities.

\subsection{Testing Regulation Supply}

Midwest ISO tested its ancillary service markets and its ability to control the balancing area weekly, and Warrick tested its ability to provide regulation since late August. Much has been learned about both the aluminum plant's ability to provide regulation and the Midwest ISO's use of the service.

\subsubsection{Midwest ISO Use of Regulation}

The Midwest ISO regulation signal to APGI is shown in Figure 16 for six tests. While the signal has abrupt state changes the Midwest ISO assumes that the load or generator will ramp to the new set-point so the actual required regulation is a bit smoother than these plots show. It is easier to visualize the differences, however when this control signal, rather than the expected response, is plotted.

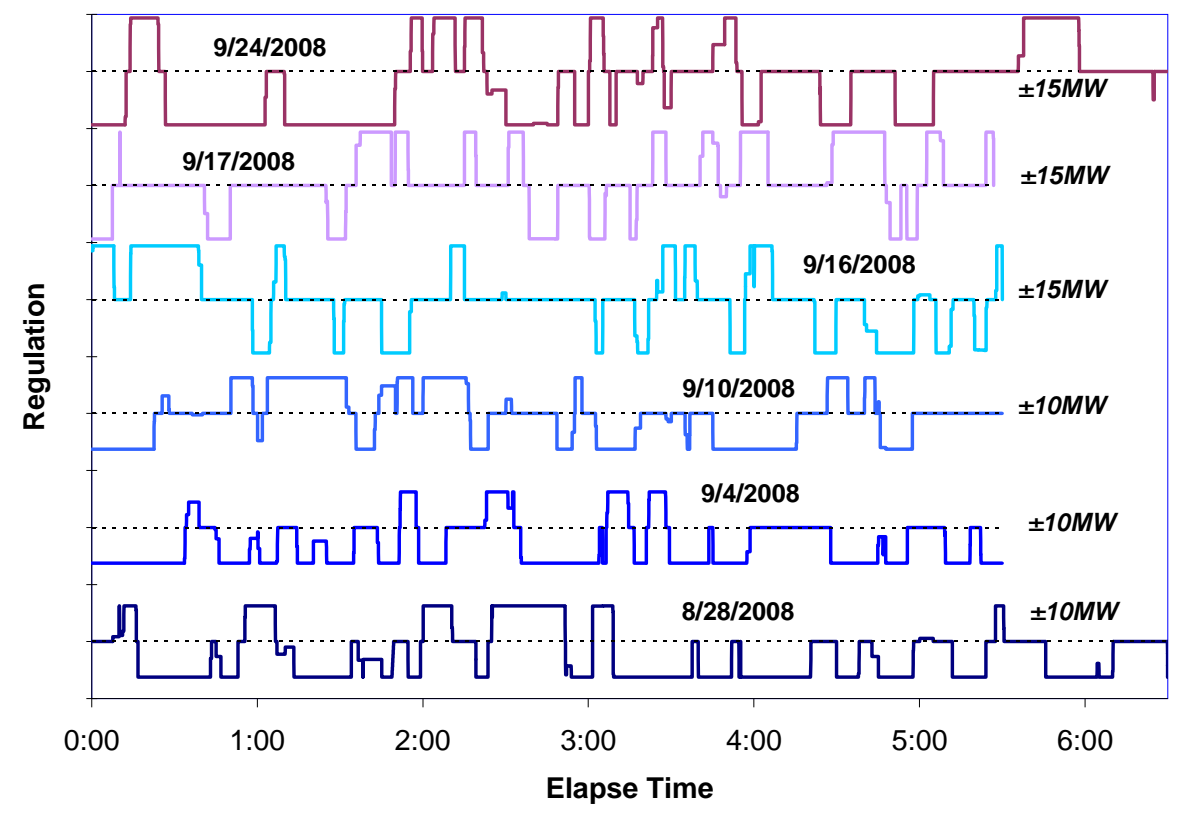

Figure 16. Six Midwest ISO regulation tests 
Several features stand out from the plot. Regulation is a relatively slow service for the Midwest ISO. It does not cross back and forth over the zero line every few minutes which is common for many BAs. Figure 17 confirms the observation and shows that the Midwest ISO controls the load down for long periods (30 to 40 minutes) for a surprisingly large percentage of the time. Figure 17 does not show that the Midwest ISO often repeats multiple periods of regulating the load down with only short intervals between. This is evident from

Figure 16.

It appears that the Midwest ISO is using regulation as an energy source. This observation is confirmed in Figure 18 which shows the cumulative energy being supplied by the regulating resource. Cumulative energy stays near the zero axis and crosses back and forth for three of the test days: September 10,16, and 17. Cumulative energy shows that the Midwest ISO was constantly extracting energy from the regulation resources on August 28, September 4, and September 24. Six tests are too few to establish a trend but it appeared as though the Midwest ISO might have been getting better in its use of regulation from late August through September 17. Nevertheless, the September 24 test results show that Midwest ISO may have returned to the practice of using regulation as an energy resource.

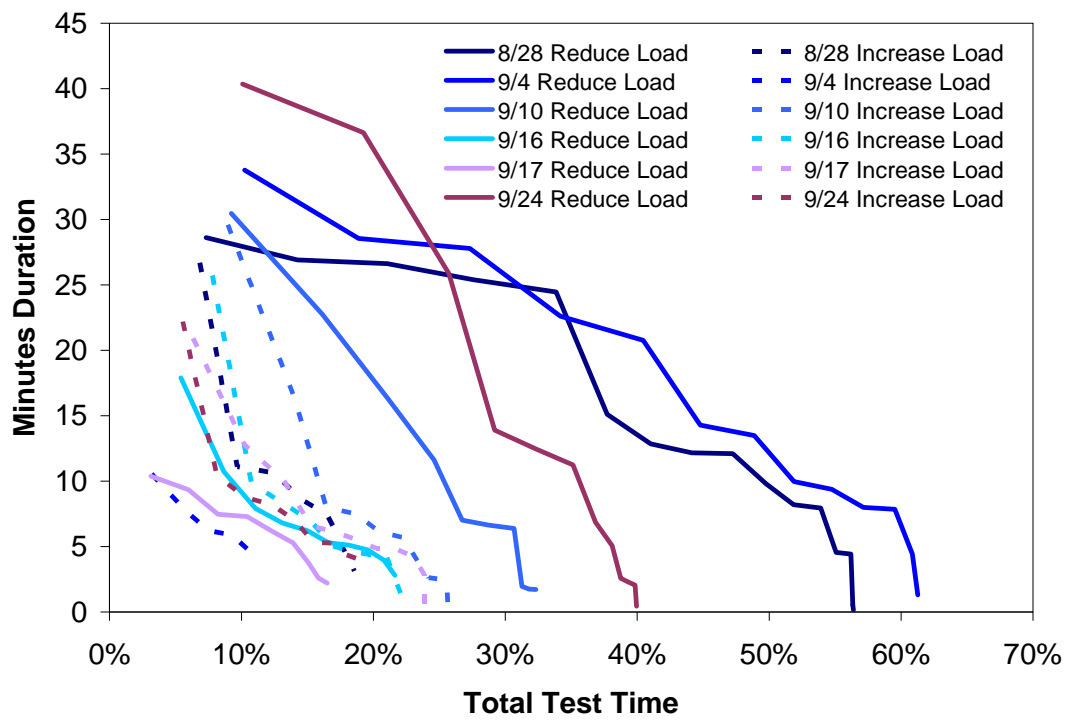

Figure 17. Cumulative regulation swing duration. 


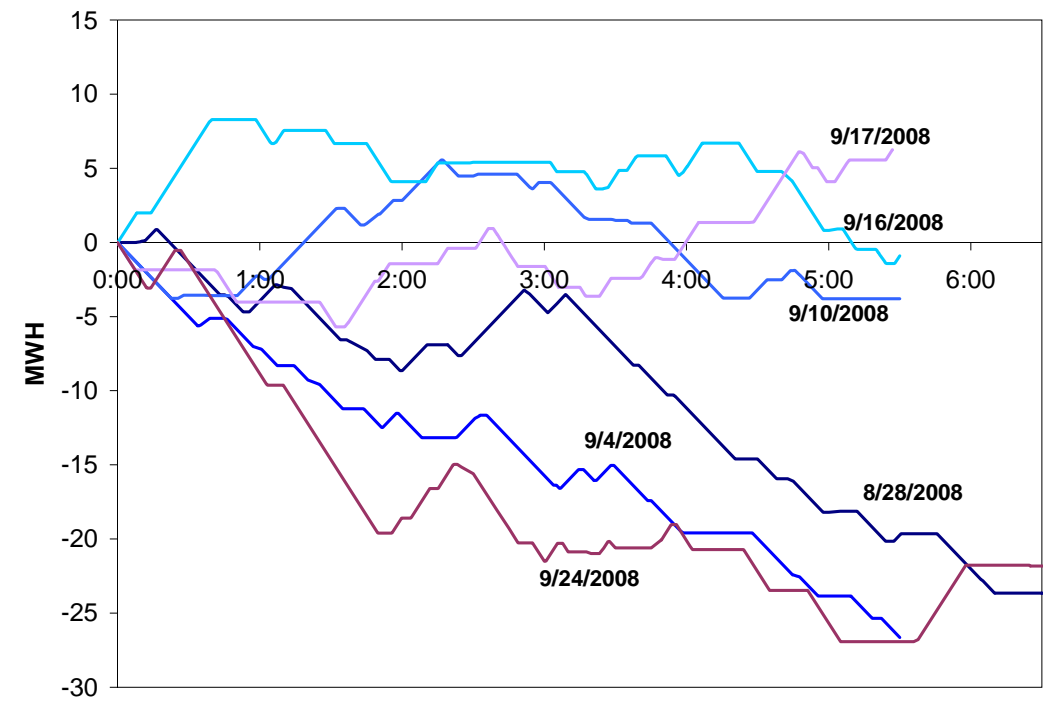

Figure 18 Midwest ISO was using regulation to obtain energy on three of the six test days.

\subsubsection{Warrick Provision of Regulation}

Warrick began testing the supply of $10 \mathrm{MW}$ 's of regulation, has progressed to supplying $15 \mathrm{MW}$, and will continue to increase levels of participation as the market evolves. Regulation supply is working quite well, especially considering the tap changer technology that is being use to control the load.

Ten MW regulation supply is shown in Figure 19 and 15 MW regulation supply is shown in Figure 20. Figure 21 shows the effects of a potline interruption while supplying regulation. The plant recovered fairly quickly with the regulation trend being followed within ten minutes of the interruption and being fully back on schedule within 35 minutes.

Figure 8 showed that aluminum smelter load is relatively flat, but that is flat relative to the total load. Normal variation is about $1 \%$ of the total load, but that same normal variation is in the order of $20-25 \%$ of the regulation signal when providing 10 to 15 MW's of regulation. This is why the regulation response appears a bit noisy and the control system had to be tuned to account for the normal variation, in addition to the controllable set point changes.

Furthermore, APGI has also shown that while providing regulation, a single potline can be opted out without failure in meeting regulation requirements and that peak shaving can be performed. These are significant achievements in demonstrating the demand response capability of the aluminum smelter and the efforts of APGI to enhance power system reliability. 


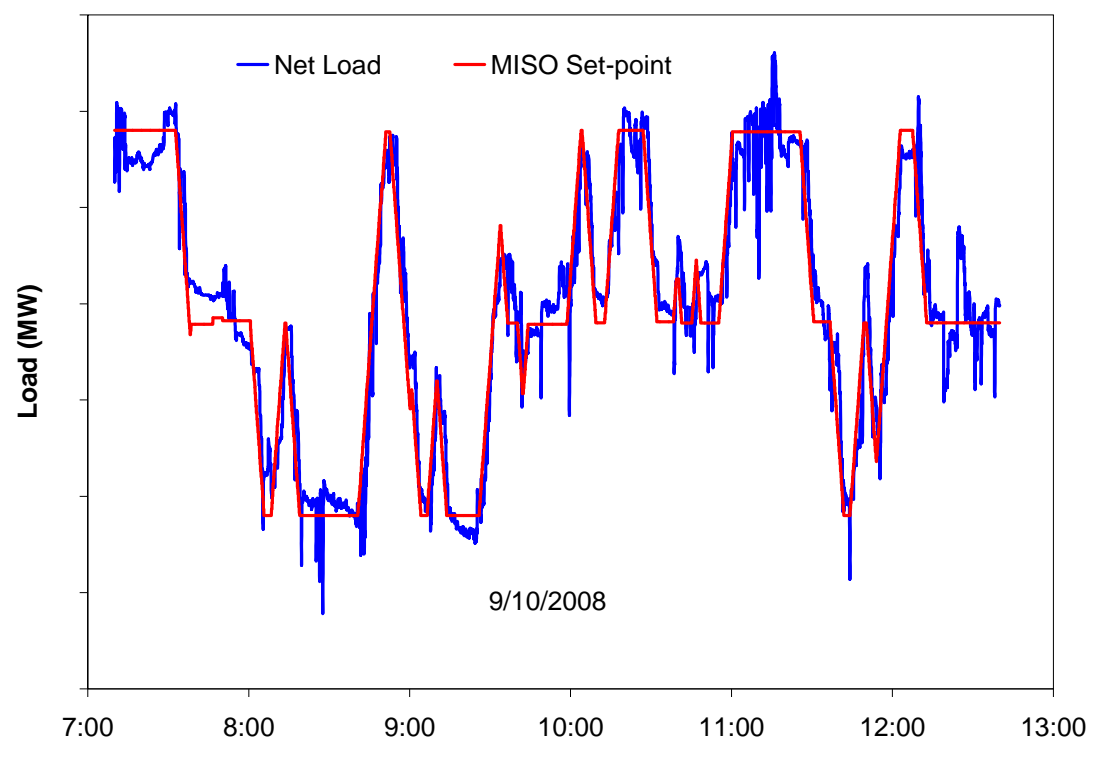

Figure 19 Supplying $10 \mathrm{MW}$ of regulation.

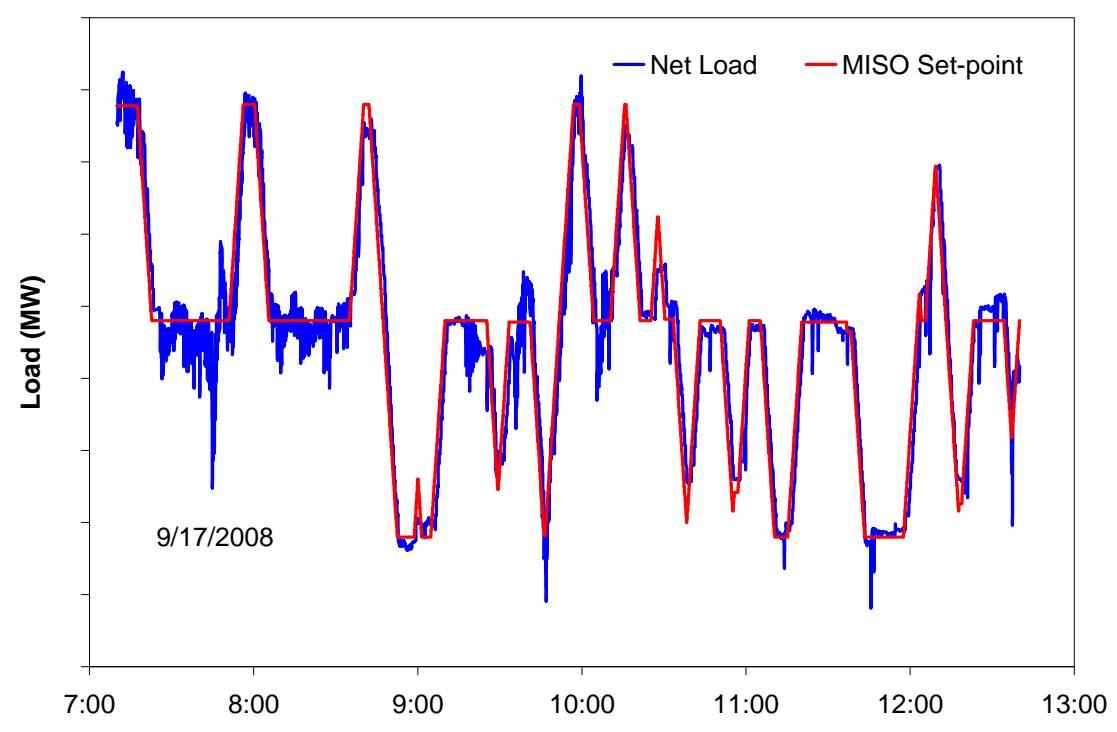

Figure 20 Supplying 15 MW of regulation. 


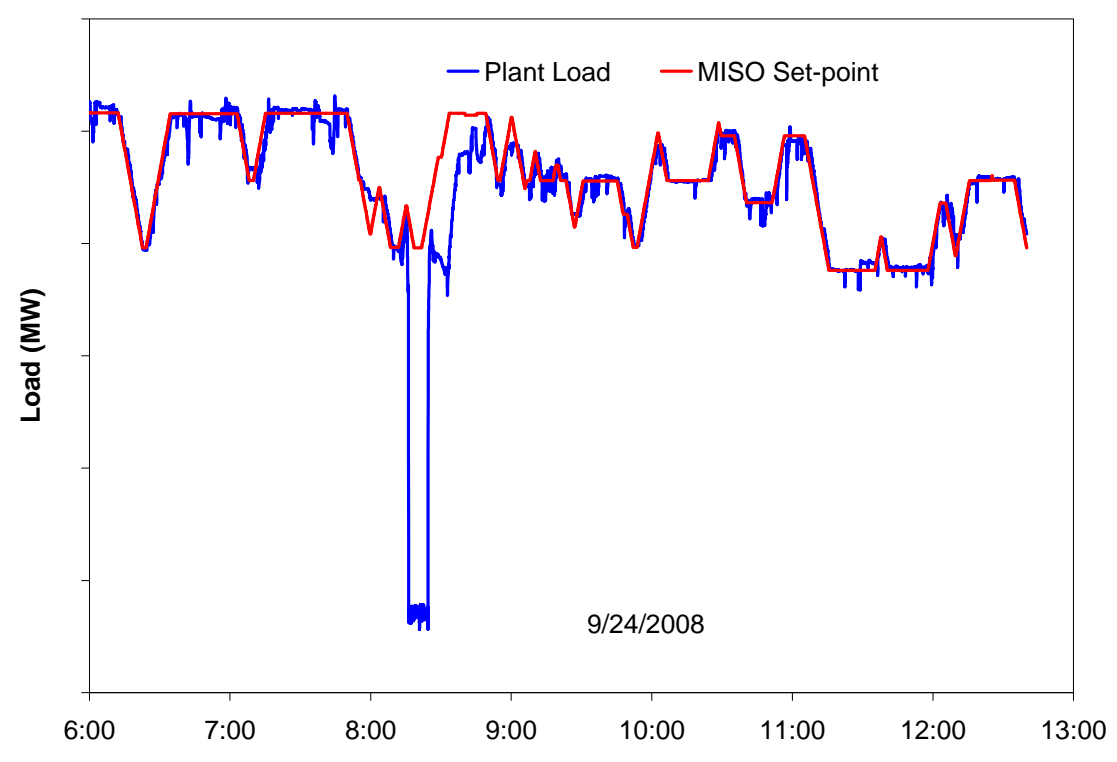

Figure 21 Potline interruption while supplying regulation.

\subsection{Control Strategies}

Ideally, Alcoa smelters prefer to have their load maintained at a constant power with minimal variation. In this way, each potline is monitored and adjustments to each specific potline can be conducted to furnish the pots with a strict thermal balance. However, to provide the regulation service, the smelter must embrace fluctuations. APGI implements control structures that retain the pots within a strict thermal balance, even during events of extended regulation up and regulation down.

For periods of regulation up, where the load exceeds the normal average, APGI permits the pots to absorb excess energy. Similarly, during intervals of down regulation, the pots are allowed to cool. Preemptively, APGI also adopted additional control strategies for extended misuse of regulation and to handle routine maintenance. This includes pot rotations and adjustment of the regulation in the market.

Potline rotations involve removing one pot-line from operation to reduce the overall load and allow a particular pot to cool. Once the pot has cooled enough, the pot-line is reinserted into the system and another pot-line can be removed. APGI can also adjust the forecast of the amount of available regulation. The Midwest ISO has provided APGI with the capability to alter the amount of regulation when ample warning is provided. However, if these methodologies cannot be utilized, APGI can opt out of providing regulation and face a fine in lieu of damaging the pots. 
Along with determining the necessary strategies in the practicality of providing regulation, APGI also had to examine the economic opportunities in providing regulation. Since APGI has the capability to both buy and sell energy on the Midwest ISO energy market, APGI examines the factors that contribute to the cost of aluminum and energy at Warrick Operations. These factors include:

- the price of aluminum

- the price of coal

- the allowance for $\mathrm{SO}_{2}$

- the allowance for $\mathrm{NO}_{\mathrm{x}}$

- the price of natural gas

- the impact on pot-lines from shaving and rotations

- the impact on boiler efficiency due to operation at reduced capacity.

Before the existence of the energy market, APGI mainly focused on generating enough energy to supply the local demand of the smelter and rolling mill. However, the Midwest ISO energy market, as previously mentioned, has given APGI the opportunity to adapt the generation techniques to minimize costs and increase profits.

APGI has developed a real-time power procurement strategy based on the economic factors of aluminum production. One such strategy is shown in Table 7. APGI purchases energy from the market and ramps down generation when power prices are low, utilizing the cheap energy from the market to supply the smelter. APGI attempts to sell energy to the market through ramping up generation when market prices are high. When energy market prices exceed a predetermined point, APGI finds it more economical to reduce aluminum production and begins peak shaving in order to sell additional electricity. If prices rise above an even higher price point, Warrick Operations will employ pot rotation mechanisms to minimize the load and maximize electricity sales. Normal operations occur when the price of generation equals the acceptable price of energy for aluminum production. Within this operating framework, the boilers are operated to optimize efficiency.

\subsection{Regulation Effects on Production}

During the preliminary tests of providing regulation to the Midwest ISO market, no apparent added environmental effects have been visible. There was a concern that additional $\mathrm{CF}_{4}$ (a harmful compound to the environment) would be generated when providing regulation. This compound is created when excessive current densities are passed through the pot leading to insufficient aluminum oxide. Process control has prevented this adverse environmental impact. 


\begin{tabular}{|c|c|}
\hline $\begin{array}{l}\text { Power Cost } \\
\text { Trigger } \\
\text { Points }\end{array}$ & APGI Marketing Procedures \\
\hline$\$ X X+$ & Interrupt Potline Load \\
\hline$\$ X X-\$ X X$ & Shave Potline Load \\
\hline$\$ X X-\$ X X$ & Maximize Behind the Meter Generation \\
\hline$\$ X X-\$ X X$ & $\begin{array}{l}\text { Balance Load with Generation } \\
\text { (Power = Production Cost) }\end{array}$ \\
\hline$\$ X X-\$ X X$ & $\begin{array}{l}\text { Reduce Behind the Meter Generation } \\
\text { (Power < Production Cost) }\end{array}$ \\
\hline$\$ X X-\$ X X$ & Minimize Behind the Meter Generation \\
\hline$<\$ X X$ & Increase Potline Load to Maximum \\
\hline
\end{tabular}

Table 7. Alcoa Power Generating, Inc. Energy Market Analysis

Although it is clear that regulation can be successfully deployed for short durations (5-6 hrs), the long term (multi-day) effect on process efficiency is still unknown. Due to the large number of factors that contribute to the production of aluminum, measuring the change in efficiency of aluminum production over short periods, such as the six hour test provided by Midwest ISO, is extremely difficult to conduct. Therefore, until APGI has sufficient experience with the newly launched Midwest ISO ancillary service market, APGI will not be able to evaluate the effects of regulation on process efficiency.

A recognized concern has been the impact on the rectifier tap changers, since the adjustments to amperage is achieved by movement of mechanical tap changers on the rectifier stations. While the rectifier has normal tap changer movements that are part of the constant adjustments to optimize the unit, data from the Warrick plant indicates that increases in movements could be as large as $500 \%$ per day during active regulation of 15 MW's (Figure 22). 


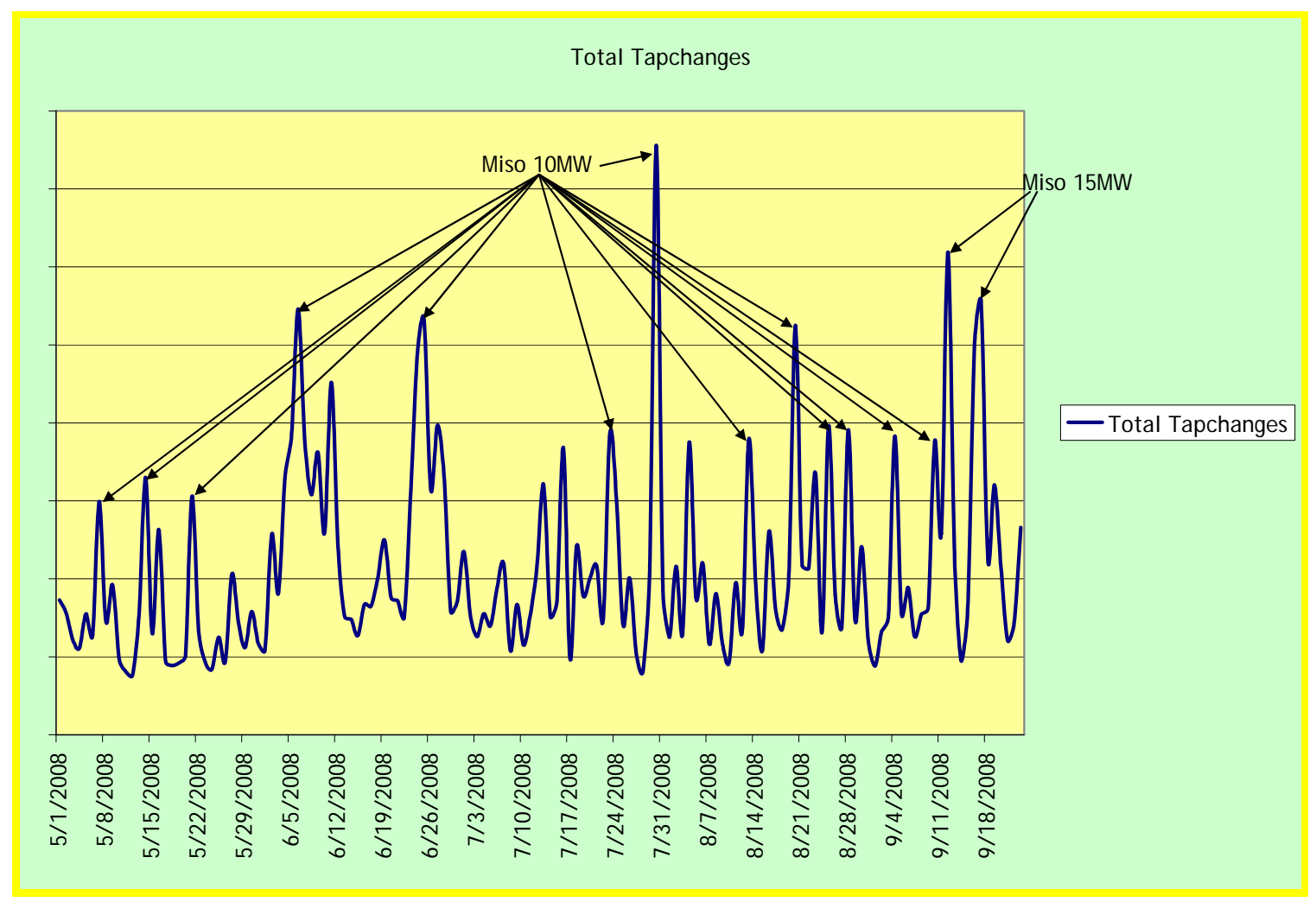

Figure 22 Providing regulation significantly increases potline tap changer movements. 


\section{FUTURE PLANS AND EXPECTATIONS}

The effort described in this report is in the very early stages. Near-term efforts will focus on refining the existing Warrick plant capabilities. Mid-term efforts will focus on expanding plant capabilities through plant and process enhancements. Long-term efforts will focus on exploring the full potential of an unconstrained process to minimize aluminum production cost by maximizing the ability to supply regulation and other ancillary services.

\subsection{Near-Term Plans}

Both the Midwest ISO ancillary service markets and the Warrick plant capabilities need to be fully understood before Warrick can refine the process control and regulation provision. The Midwest ISO ancillary service markets and BA operations just started in January 2009. Experience with the startup of other energy and ancillary service markets indicate that the Midwest ISO ancillary service market is not likely to settle into final stable performance until three to six months after the market goes live and all participants are risking real money. Warrick will continue participating in the Midwest ISO markets to both refine its market strategy and to refine the process control.

Additionally, the Midwest ISO itself is likely to require some time as the operator of such a large BA to refine its own use of regulation. NERC will have to determine if the Midwest ISO and the other BAs can continue operating under the BAAL standard, if it must go back to CPS1\&2, or if there will be another set of balancing requirements imposed. It seems likely that the Midwest ISO will migrate to using regulation as a minute-to-minute service and will obtain load following and energy from the five-minute energy market. It is possible that responsive loads will be granted the same market rule treatment as storage.

Now that the Midwest ISO has commenced full time operation of the BA, Warrick can begin fully characterizing the impact provision of regulation has on process efficiency and maintenance requirements. Because these impacts are subtle they can be masked by normal variations in process conditions. Warrick will likely have to operate for several days in a row providing regulation and several days in a row not providing regulation

with all other parameters kept as constant as possible. Standard production metrics for both intervals can then be compared.

This near-term effort will characterize the impact of regulation on plant efficiency, productivity, maintenance costs, and most importantly on opportunity costs. This will be an iterative process that will refine the process control to maximize regulation while minimizing costs. Provision of regulation will be fully incorporated into the process that currently works so well to optimize energy purchases and electricity production. Realtime analysis of the opportunity costs of supplying regulation will be compared with the offered regulation price to select the optimal plant position in both markets. 


\subsection{Mid-Term}

Once the process capabilities and impacts are fully understood and once the Midwest ISO ancillary service market becomes sufficiently stable to allow reasonable forecasting of regulation prices it will be possible to study potential plant enhancements to profitably increase the ability to supply regulation. Both electrical system and process improvements will be candidates.

Methods to increase the range of voltage control will be examined. Possibilities include tap changer improvements, saturable reactors, solid state devices in the switch yard such as static VAR compensators, and solid state power supplies for the potlines.

Potential process improvements include methods to enhance pot control and stability, equipment to extend the acceptable power range, equipment to enhance the thermal balance as power levels swing.

The Warrick and both Massena plants will be studied to determine what potential each has for supplying regulation.

The value to the power system of faster, more accurate regulation will also be quantified. The quality of regulation that an aluminum smelter can provide is significantly greater than the quality of regulation that the typical large coal fired power plant can provide. High quality regulation should reduce total system regulation requirements and costs. The power system operator should be willing to pay a premium for higher quality regulation. Both the increased quality of smelter provided regulation and the increased value need to be quantified.

\subsection{Long-Term}

A preliminary scoping study will be useful to quantify the potential benefits of maximizing the supply of regulation. This can be coupled with a flexible plant conceptual design that incorporates new pot designs that are themselves optimized not exclusively for maximum aluminum production but also for maximum flexibility. Taken together these two efforts will quantify both the required flexibility and potential benefit for supplying large amounts of regulation. Experience from operation in the Midwest ISO market will also show how that flexibility can be used. If the benefits are as large as expected a research and development program can be initiated to design and build a nextgeneration aluminum smelting process with the potential to make aluminum production in the U.S. viable in the long term. 


\section{CONCLUSIONS AND RECOMENDATIONS}

Responsive load remains the largest underutilized reliability resource available to the North American power system today. Many loads have response characteristics that are technically well matched to the power system reliability needs. Unfortunately, market and reliability rules were developed when generators were the only resources available to the system operator. Consequently those rules often prohibit load response, especially for the fastest, most critical, and most expensive reliability services. The rules are also often specified in terms of the capabilities and limitations of generators rather than around the functional reliability needs of the power system.

Alcoa engaged in an extensive and expensive effort to enable the Warrick plant to supply minute-to-minute regulation to the power system. The plant proved that the process can supply fast and accurate regulation, even with existing power supply equipment. While the use of tap changers to rapidly and frequently control potline voltage is not ideal the results exceed the quality of regulation conventional generators can supply. Preliminary plant performance results are impressive.

The delay in the start of the Midwest ISO ancillary services market has necessarily delayed the full evaluation of the cost of supplying regulation from Warrick. While process impacts are apparently modest a full assessment can not be performed until experience is gained with the Midwest ISO operating as a balancing area on a continuous basis and purchasing regulation continuously. A full economic analysis can not be performed until the Midwest ISO ancillary service market is operating and stable. The market went live in January 2009 and may take three to six months to fully stabilize. Once the Midwest ISO is fully regulating, Warrick can quantify the regulation supply costs.

The Midwest ISO's preliminary use of regulation during market testing presents one concern. Regulation is expected to move randomly minute-by-minute around a central point with balanced up and down movements when averaged over one to several hours. The Midwest ISO tended to hold the regulation signal in one direction for extended periods and used more generation-up (load-down) regulation than generation-down. In short, the Midwest ISO had been using regulation for load following and for energy during the limited testing. It is to be hoped that the Midwest ISO will refine its use of regulation if for no other reason than regulation is an expensive way to get load following and energy. None the less, Alcoa can tailor its regulation offering to match whatever regulation characteristics the Midwest ISO ends up requiring.

As experience is gained in the near term the plant's ability to supply regulation can be expanded in the mid-term. Ultimately supplying regulation has the potential to transform the U.S. aluminum smelting industry. 


\section{ACKNOWLEDGMENT}

This work was coordinated by the Consortium for Electric Reliability Technology Solutions for the U.S. Department of Energy, Office of Electricity Delivery and Energy Reliability. It is based upon research efforts concerning ancillary services and responsive load which has been supported for many years by Phil Overholt and the Department Of Energy. Thanks go to Fangxing Li, and Travis Smith for reviewing a draft of the paper. 


\section{REFERENCES}

1. M. DePillis, 2006, The New Ancillary Services Markets of New England, MIDWEST ISO Ancillary Services Round Table, 26 April

2. FERC 1996, Promoting Wholesale Competition Through Open Access Non-discriminatory Transmission Services by Public Utilities; Recovery of Stranded Costs by Public Utilities and Transmitting Utilities, Order 888, Federal Energy Regulatory Commission, May

3. FERC Staff, 2006, Assessment of Demand Response and Advanced Metering, Federal Energy Regulatory Commission, Docket AD-06-2-000, August

4. E. Hirst and B. Kirby, 2003, Opportunities for Demand Participation in New England Contingency Reserve Markets, New England Demand Response Initiative technical paper, February

5. B. Kirby, M. Milligan, 2008, The Impact of Balancing Area Size, Obligation Sharing, and Energy Markets on Mitigating Ramping Requirements in Systems with Wind Energy, Wind Engineering Volume 32, No. 4

6. B. Kirby, 2006A, The Role of Demand Resources In Regional Transmission Expansion Planning and reliable Operations, ORNL/TM-2006/512, Oak Ridge National Laboratory, July

7. B. Kirby, 2006B, Demand Response For Power System Reliability: FAQ, ORNL/TM2006/565, Oak Ridge National Laboratory, December

8. B. Kirby, 2003, Spinning Reserve From Responsive Loads, ORNL/TM-2003/19, Oak Ridge National Laboratory, March

9. B. Kirby and E. Hirst, 2003, Technical Issues related to Retail Load Provision of Ancillary Services, New England Demand Response Initiative technical paper, February

10. J. Kueck and B. Kirby, 2005, Presentation to the WECC CMOPS, 7 January

11. J. Kueck and M. Patterson, 2006, telephone interview, October

12. J. Mickey, 2006, Competitive Ancillary Services Market in ERCOT, MIDWEST ISO Ancillary Services Round Table, 26 April

13. Metals Advisor, 2008, Drawing found on: http://www.energysolutionscenter.org/heattreat/metalsadvisor/aluminum/process_descriptio ns/anode_baking.htm

14. http://www.energysolutionscenter.org/heattreat/MetalsAdvisor/aluminum/mining_and_prim ary_processing/mining_and_primary_process_description.htm

15. Midwest ISO 2006, Ancillary Services Round Table, Midwest Independent System Operator, Carmel Indiana, April 26-27 
16. NERC, 2007, Data Collection for Demand Side Management for Quantifying Its Influence on Reliability: Results and Recommendations, North American Electric Reliability Corporation, December

17. NERC, 2006A, Glossary of Terms Used in Reliability Standards, North American Electric Reliability Council, Princeton, NJ, May 2

18. NERC, 2006B, Reliability Standards for the Bulk Electric Systems of North America,

19. North American Electric Reliability Council, Princeton, NJ, February 7, Downloaded from www.nerc.com on 20 March, 2006

20. N. Trehan, R. Saran, "Electric Utility Deregulation: Failure or Success," IEEE Nuclear Science Symposium Conference, Vol. 4, Oct. 2004, page(s): 4614-4617.

21. Midwest Independent Transmission System Operator Ancillary Service Market Business Rules, Final Version, February 6, 2007. Downloaded from www.Midwestiso.org in August 2008.

22. Midwest Independent Transmission System Operator Corporate Information, April 2008. Downloaded from www.Midwestiso.org in August 2008.

23. FERC, Balancing authorities in the Midwest Electric Market, Dowloaded from:

24. http://www.ferc.gov/market-oversight/mkt-electric/midwest/elec-mw-list.pdf

25. "Reliability Standards for the Bulk Electric Systems of North America", 2008, North American Electric Reliability Corporation, 116-390 Village Blvd., Princeton, N.J, downloaded from http://www.nerc.com/files/Reliability Standards Complete Set 1Dec08.pdf

26. Forbes magazine: fownloaded
http://www.forbes.com/forbes/2003/1110/090chart.html 